\title{
Further tests of asset pricing models: Liquidity risk matters
}

\begin{abstract}
The recent asset pricing literature has largely neglected liquidity risk since the price-impact-based factor shows limited pricing ability. Using different liquidity factors, this paper evaluates the liquidity-risk-based models together with the nonliquidity-based ones. With the new testing procedures and the different testing portfolios, we find that the liquidity-augmented capital asset pricing model (LCAPM) performs well. It yields a significant liquidity risk premium robust to all the other models. The success of the LCAPM lies in the fact that the trading-discontinuity-based factor captures the systematic nature of liquidity risk. It shows that liquidity risk is priced highly during the down and turmoil markets, whereas all the other factors examined exhibit insignificant risk prices when market volatility is high. Our evidence indicates that liquidity risk matters and the LCAPM is preferable to use for investment decision making, financial market research and regulation.
\end{abstract}

Keywords: Liquidity risk; Asset pricing models; Model performance

\section{Introduction}

Liquidity has long attracted attention in the finance literature. It shows that liquidity affects asset returns through two different channels: liquidity level effect and liquidity risk effect. The level effect shows that illiquid stocks tend to earn higher average returns than liquid ones 1 The risk effect reveals that stocks with high exposure to shocks in market liquidity command a premium relative to stocks with low exposure, inline with the argument about the importance of liquidity risk in asset pricing (Pástor and Stambaugh, 2003; Acharya and Pedersen, 2005; Liu, 2006; Sadka, 2006; and Lee, 2011). However, recent development in asset pricing has largely overlooked liquidity risk. For instance, the developments of the Fama and French (2015) five-factor model (FF5) and the Hou, Xue, and Zhang (2015) four-factor model (HXZ4) do not consider liquidity risk. This is because they find that the loadings of assets on the Pástor and Stambaugh (2003) (PS) liquidity factor are close to zero and the PS factor yields little improvement in model performance. Fama and French (2016), Hou et al. (2017), Momani (2018), and Ahmed et al. (2019) also use the PS liquidity factor as a representative and show that liquidity risk is not priced. Nevertheless, there are other liquidity risk factors/models proposed in the literature such as the Sadka (2006) price-impact-based factor and the Liu (2006) trading-discontinuity-based factor. Therefore, this paper addresses the question: Is liquidity risk negligible for asset pricing if also considering other liquidity risk factors/models? Specifically, this study explores whether different liquidity

\footnotetext{
${ }^{1}$ Examples are Amihud and Mendelson (1986), Brennan and Subrahmanyam (1996), Datar, et al. (1998), Brennan, et al. (1998), Amihud (2002), Liu (2006), Bekaert, et al. (2007), Hasbrouck (2009), Lou and Sadka (2011), and Corwin and Schultz (2012).
} 
risk factors or liquidity-risk-based models proposed in the literature perform differently, and whether the liquidity-risk-based models well explain the cross-section of stock returns in comparison with non-liquidity-risk-based pricing models.

The importance of liquidity risk in asset pricing is economically intuitive. This is because liquidity risk arises from consumption and solvency constraints. When the economy performs poorly, causing market liquidity to dry up, investors may have to liquidate their investment for consumption. Also, during the bad times, investors with solvency constraints may have to honor their obligations by converting their investment into cash. If stocks investors hold are highly sensitive to market liquidity shocks, these forced liquidations can result in significant losses, i.e., investor may have to liquidate their positions at unfairly low prices, especially during the liquidity crisis. As a result, liquidity risk is likely to affect investors' decision marking. Unless investors are expecting to earn high returns, they will not invest in stocks with high exposure to liquidity risk. Indeed, studies show significantly impact of fluctuations in market liquidity on the constructions of investment portfolios (Garleanu and Pedersen, 2013; Dong et al., 2019), the costs of capital (Butler et al., 2005), and the capital structure decisions (Lipson and Mortal, 2009). Why do researchers find insufficient pricing ability of liquidity risk? The answer may lie in the usual choice of the PS factor/model as a representative in testing the pricing power of liquidity risk. The PS liquidity factor is constructed based on the price impact measure of liquidity (i.e., the sensitivity of price changes to trading volume). However, liquidity is multidimensional, including trading costs, trading impact on price, trading quantity, and trading speed. Hence, the price impact measure may not be able to fully characterize liquidity. It seems that the empirical evidence supports this claim, e.g., Pástor and Stambaugh (2003) mention that their price impact measure does not command a significant premium at individual stock level, and Ben-Rephael et al. (2015) find that the liquidity proxies associated with trading costs and price impact dimensions are not robust to generate a significant premium. Therefore, different liquidity factors/models can have different pricing abilities.

For liquidity risk factors/models, we investigate three published ones. The first is the PS liquidity factor, which its construction relies on their liquidity proxy capturing the impact of trading on price, i.e., price impact. The PS liquidity risk model has four factors: the Fama-French three factors plus the PS liquidity factor. The second is the Sadka (2006) liquidity factor. The construction of the Sadka factor is also based on the price impact concept. With his liquidity factor, Sadka extends both the capital asset pricing model (CAPM) and the Fama-French three-factor model (FF3). The third is the Liu (2006) liquidity-augmented CAPM (LCAPM) with the liquidity risk factor being constructed based on his trading discontinuity measure of liquidity. Because liquidity is multi-dimensional and different dimension may not be equally important to describe liquidity, liquidity factors stemmed from different liquidity proxies and the corresponding liquidity extended models are likely to exhibit different power to capture liquidity risk and to explain the cross-section of expected stock returns. As discussed and empirically confirmed by Liu (2006), the trading discontinuity measure reflects lock-in risk, captures multi-dimensions of liquidity, and yields the most pronounced liquidity premium robust to existing models. Therefore, the trading-discontinuity-based liquidity risk model, i.e., 
the LCAPM, seems likely to have the consistent power to capture liquidity risk and to explain the cross-section of average returns. For comparison, we also assess the popular or likely to be popular models including the FF3, the momentum-extended FF3 of Carhart (1997), the HXZ4, and the FF5, which some of these are also included in a series of model evaluation studies (Fama and French, 2018; Barillas and Shanken, 2018; Ahmed et al., 2018; Barillas et al., 2019; Fall et al., 2019; Hou et al., 2019; Sha and Gao, 2019).

Empirically, we first test the pricing ability of liquidity-risk-based models. Traditionally, researchers commonly adopt the Fama-MacBeth two-stage regression procedure with the implicit assumption of correctly specified models. Since there are many pricing models proposed in the literature (see Harvey et al., 2016), it is unlikely that they are all correctly specified. Thus, tests based on the assumption of correctly specified models may lead to erroneous inferences, as pointed out by Shanken and Zhou (2007), Kan et al. (2013), and Gospodinov et al. (2013). Consequently, apart from the traditional test procedure, we also evaluate the significance of factor risk premiums based on the misspecification-robust standard error of Kan et al. (2013). In addition, we investigate whether a particular factor in a multifactor model significantly contribute to the model's explanatory power. As in Kan et al. (2013), we examine the cross-sectional relation between expected returns and beta risk as well as covariance risk ${ }^{2}$ With different sets of testing portfolios formed on the common firm characteristics the results show that among the three liquidity factors/models, the trading-discontinuity-based liquidity risk factor of the LCAPM shows stable pricing ability, i.e., the risk premiums associated with both the beta risk and covariance risk are statistically and economically significant. Consistently, the LCAPM explains average asset returns well. For the price-impact-based PS and the Sadka (2006) factors, on the other hand, the premiums related to both the factor loading and the covariance risk tend to be insignificant in most cases. This is inline with our conjecture and other studies, liquidity factors constructed with different liquidity proxies can perform differently, and the price-impact-based ones exhibit limited power to account for expected returns. For completeness, we also test the non-liquidity-risk-based factors/models. In general, the firm characteristics-based factors such as the ones of FF5 and HXZ4 show good performance against the test portfolios formed on these characteristics. However, there is evidence that inferences about the pricing ability of certain factors are sensitive to the testing assumptions. Taking the momentum factor as an example, the significant risk premium becomes insignificant with the 25 size and book-to-market portfolios under the model misspecification assumption.

Second, we assess the performance of liquidity-risk-based models in comparison with non-liquidity-risk-based pricing models. Our assessments employ the maximum squared Sharpe ratio metric, $S h^{2}(f)$, a testing technique newly proposed by Barillas and Shanken (2017) and Barillas et al. (2019). Sharpe ratio is a key variable in portfolio theory so that the $S h^{2}(f)$ test is not only

\footnotetext{
${ }^{2}$ Kan et al. (2013) argue that testing a factor's pricing ability is different from investigating its contribution to the model's explanation for average returns. To examine a factor's role in improving the model's explanatory power, one should test whether the factor's covariance risk price is significantly different from zero.
} 
helpful for evaluating model performance, but it is also of interest in making capital allocation decisions. The testing results show that the LCAPM and the HXZ4 stand out from all the other models considered. The trading-discontinuity-based liquidity risk factor of the LCAPM yields the largest contribution in improving the $S h^{2}(f)$ metric of the HXZ4 and the FF5 across all competing factors examined.

Additionally, we investigate the performance of pricing factors/models related to different economic conditions measured by the stock market excess returns and stock market volatility. Studies have documented that liquidity dry-up occurs during periods of market downturns and large market volatility (e.g., Pástor and Stambaugh, 2003; Liu, 2006; and Hameed et al., 2010). Næs et al. (2011) argue that, in addition to requiring a premium, liquidity risk pricing should reflect the business cycle. Our results reveal that the liquidity factor of the LCAPM lends support to the relation between liquidity risk and market conditions: investors price liquidity risk high during market downturns and turbulent times. In contrast, the price-impact-based liquidity factors of Pástor and Stambaugh (2003) and Sadka (2006) do not show such a tendency across the different economic states. In addition, the liquidity factor of the LCAPM yields the highest marginal $S h^{2}(f)$ among competing factors when the market performs poorly. High $S h^{2}(f)$ during the falling markets can be viewed as compensation for liquidity providers, as commented by Hameed et al. (2010). We also explore whether the information captured by the liquidity factors can be subsumed by other factors. The results show that, under each market condition, none of the other factors/models accounts for the liquidity factor of the LCAPM, confirming the uniqueness of liquidity risk for asset pricing.

Our study complements existing research on the importance of liquidity risk in asset pricing. Different from many existing studies that examine the liquidity premium with different liquidity proxies or compare different measures, our focus is on whether liquidity risk is negligible to explain average stock returns relative to the popular or likely to be popular models. Our results supplement a series of recent studies on the evaluation of asset pricing models (Fama and French, 2016; Hou et al., 2017, 2019; Ahmed et al., 2019; Sha and Gao, 2019; Fall et al., 2019; Feng et al., 2020; Li et al., 2019), which either neglect liquidity risk or use the PS factor as the only representative to capture liquidity risk. With the PS liquidity factor/model, these studies generally rule out the importance of liquidity risk in asset pricing. In contrast, our results differ from these studies by showing that the trading-discontinuity-based liquidity factor is robust to all other models considered, implying that liquidity risk is an essential risk source non-ignorable for asset pricing. Indeed, the corresponding LCAPM performs no worse but generally better than the commonly and likely to be commonly used models. Our findings have important practical implications since an adequate pricing model is crucial to corporate investment appraisal, portfolio construction, performance evaluation, and financial economics research such as tests of market efficiency.

The remainder of the paper is organized as follows. Next section introduces research methods used for empirical analysis. Section 3 describes the factor models. Section 4 reports the empirical evidence on the factor pricing ability tests. Section 5 
conducts tests based on the $S h^{2}(f)$ metric. Section 6 conducts additional tests. Section 7 concludes.

\section{Research method}

\subsection{The framework of Kan et al. (2013)}

The linear asset pricing model describes the relation between the excepted return of an asset and systematic risks. With $K$ risk factors, the arbitrage pricing theory (APT) is:

$$
E\left(R_{i}\right)=\gamma_{0}+\sum_{k=1}^{K} \beta_{i, k} \gamma_{k}, \quad i=1, \ldots, N,
$$

where $E\left(R_{i}\right)$ is the expected return of asset $i, \beta_{i, k}$ is the factor loading of asset $i$ on factor $k, \gamma_{k}$ is the risk premium associated with risk factor $k$, and $\gamma_{0}$ is the zero-beta rate. Given the factor values, we can estimate the factor loadings by running the following time-series regression:

$$
R_{i, t}=\alpha_{i}+\sum_{k=1}^{K} \beta_{i, k} f_{k, t}+\epsilon_{i, t}, \quad t=1, \ldots, T
$$

where $R_{i, t}$ is the month- $t$ return of asset $i$ (our tests use monthly data), $f_{k, t}$ is the month- $t$ value of factor $k$, and $\alpha_{i}$ is the regression intercept of asset $i$.

Let $u$ be an $N \times 1$ vector of expected return on $N$ assets, $V_{N}$ be an $N \times N$ covariance matrix of $N$ assets, $\gamma$ be a $(K+1) \times 1$ vector consisting of $\gamma_{0}$ and $\gamma_{k}(k=1, \ldots, K), X$ be an $N \times(K+1)$ matrix which equals to $\left[1_{N}, \beta\right]$, where $1_{N}$ is an $N \times 1$ vector of ones, and $\beta$ is an $N \times K$ matrix of factor loadings associated with $K$ factors. Then, Eq. (1) can be rewritten as

$$
u=X \gamma
$$

Define $W$ as an $N \times N$ weighting matrix, the $\gamma$ is given by

$$
\gamma=\left(X^{\prime} W X\right)^{-1} X^{\prime} W u
$$

and the corresponding pricing error is

$$
e=u-X \gamma=\left[I_{N}-X\left(X^{\prime} W X\right)^{-1} X^{\prime} W\right] u,
$$

where $I_{N}$ is an $N \times N$ identity matrix.

Following Kan et al. (2013), the cross-sectional $R^{2}$ is computed by

$$
R^{2}=1-\frac{e^{\prime} W e}{e_{0}^{\prime} W e_{0}}
$$

where $e_{0}=\left[I_{N}-1_{N}\left(1_{N}^{\prime} W 1_{N}\right)^{-1} 1_{N}^{\prime} W\right] u$. 
In empirical studies, the cross-sectional $R^{2}$ is often used to assess the performance of a pricing model. When the model is correctly specified, $R^{2}=1$ (or $e=0$ ). Kan et al. (2013) derive the asymptotic distribution of sample $R$ squared $\left(\hat{R}^{2}\right.$ ), which can be used to determine whether the model has the possibility of misspecification ${ }^{3}$ An alternative method is the $F$ test. For a correctly specified model, Kan et al. (2013) show that the model's deviation $\hat{Q}=\hat{e}^{\prime} \hat{V}(\hat{e})^{+} \hat{e}$ follows an approximate $F$ distribution, where $\hat{V}(\hat{e})$ is the estimate of the covariance matrix of sample pricing error $\hat{e}$, and $\hat{V}(\hat{e})^{+}$is the corresponding pseudo-inverse. In our study, we use both methods to conduct specification test.

Traditionally, studies usually focus on whether the factor of interest produces a significant non-zero risk premium estimate. Kan et al. (2013) emphasize that when examining whether a particular factor can improve the model's explanatory power, we can examine the significance of the covariance risk price with respect to the factor. Let $C=\left[1_{N}, V_{R f}\right]$, where $V_{R f}$ is the $N \times K$ covariance matrix between the returns of testing assets $R$ and factors $f$. The cross-sectional regression model is:

$$
u=C \lambda
$$

and the covariance risk price $\lambda$ can be computed by

$$
\lambda=\left(C^{\prime} W C\right)^{-1} C^{\prime} W u
$$

Under the assumption of misspecified models, Kan et al. (2013) derive the asymptotic distribution for factor loading risk premium $(\gamma)$ and covariance risk price $(\lambda)$ (see the Appendix in their website). They also show that the model misspecification has a great influence on the asymptotic standard error of $\gamma$, especially for factors that have low correlations with testing assets. In empirical analysis, we evaluate the significance of $\gamma$ and $\lambda$ for different factors based on the misspecification-robust standard errors in Kan et al. (2013), and conduct both the OLS and GLS estimations by letting $W$ take $I_{N}$ and $V_{N}^{-1}$, respectively,

\subsection{Model comparison based on the squared Sharpe ratio metric}

According to Barillas and Shanken (2017), models with traded factors can be compared in terms of the squared Sharpe ratio metric, $S h^{2}(f)$, and a better model should produce a higher estimate of $S h^{2}(f)$. As an extension, Barillas et al. (2019) develop a pairwise comparison method to test whether two models with different $S h^{2}(f)$ estimates could give statistically equal performance ${ }^{4}$ To illustrate, suppose that there are two factor models: model A with factors $f_{A}$ and model $\mathrm{B}$ with factors $f_{B}$. We denote the maximum squared Sharpe ratios of models A and B by $S h_{A}^{2}(f)=u_{A}^{\prime} V_{A}^{-1} u_{A}$ and $S h_{B}^{2}(f)=u_{B}^{\prime} V_{B}^{-1} u_{B}$, where $u_{A}, u_{B}, V_{A}$,

\footnotetext{
${ }^{3}$ Since the asymptotic distribution of sample $R$ squared $\left(\hat{R}^{2}\right)$ depends on the actual value of $R^{2}$, Kan et al. (2013) deduce the asymptotic distribution of $\hat{R}^{2}$ under three cases: (1) $R^{2}=1$, a correctly specified model; (2) $R^{2}=0$, a misspecified model that has no power to explain expected returns; and (3) $0<R^{2}<1$, a misspecified model that has some explanatory power.

${ }^{4}$ According to Lewellen et al. (2010), evaluating pricing models based on the point estimates of testing measures is unreliable. Therefore, for models with different measurement estimates, the model performance should be determined by whether the difference in measurement estimates between two models are significantly different from zero.
} 
and $V_{B}$ are the means and covariance matrixes of the factors. The corresponding sample estimates are $\hat{S h}_{A}^{2}(f)=\hat{u}_{A}^{\prime} \hat{V}_{A}^{-1} \hat{u}_{A}$ and $\hat{S h}_{B}^{2}(f)=\hat{u}_{B}^{\prime} \hat{V}_{B}^{-1} \hat{u}_{B}$. When model A nests model B, we regress the excluded factors (included in A but not in B) on the model B factors. If the null hypothesis that the regression intercepts are jointly zero is rejected, it indicates that model A outperforms model B by generating a significantly higher estimate of $S h^{2}(f)$. If A and B are non-nested models, Barillas et al. (2019) derive the asymptotic distribution of the difference $\hat{S h}_{A}^{2}(f)-\hat{S h}_{B}^{2}(f)$ under the null hypothesis of $S h_{A}^{2}(f)=S h_{B}^{2}(f)$ as follows:

$$
\sqrt{T}\left\{\left[\hat{S h}_{A}^{2}(f)-\hat{S h}_{B}^{2}(f)\right]-\left[S h_{A}^{2}(f)-S h_{B}^{2}(f)\right]\right\} \sim N\left(0, E\left[\delta_{t}^{2}\right]\right)
$$

where $\delta_{t}=2\left(m_{A t}-m_{B t}\right)-\left(m_{A t}^{2}-m_{B t}^{2}\right)+S h_{A}^{2}(f)-S h_{B}^{2}(f)$, with $m_{A t}=u_{A}^{\prime} V_{A}^{-1}\left(f_{A t}-u_{A}\right)$ and $m_{B t}=u_{B}^{\prime} V_{B}^{-1}\left(f_{B t}-u_{B}\right)$.

Barillas et al. (2019) also develop a method to compare multiple models, i.e., testing whether a given model has a significantly higher $S h^{2}(f)$ than those of a set of competing models. Suppose there are $q$ models. Let $d=\left(d_{2}, \ldots, d_{q}\right)$, where $d_{i}=S h_{1}^{2}(f)-S h_{i}^{2}(f)$ for $i=2, \ldots, q$. The corresponding sample estimate is $\hat{d}=\left(\hat{d}_{2}, \ldots, \hat{d}_{q}\right)$ with $\hat{d}_{i}=\hat{S h}_{1}^{2}(f)-\hat{S h}_{i}^{2}(f)$. The null hypothesis is that the benchmark model (model 1) performs at least as well as the alternative models 2 to $q$, that is, $H_{0}: \delta \geq 0_{q-1}$. When the benchmark model is nested by a series of competing models, we construct an expanded model consisting of all factors from models that nest the benchmark model. If the expanded model outperforms the benchmark model by using the pairwise comparison method, it implies that one or more nested models dominate the benchmark model.

For non-nested multiple model comparisons, we construct the likelihood ratio $(L R)$ test statistic by

$$
L R=T(\hat{d}-\tilde{d})^{\prime} \hat{\Sigma}_{\hat{d}}^{-1}(\hat{d}-\tilde{d})
$$

where $\hat{\Sigma}_{\hat{d}}$ is the covariance matrix of $\hat{d}$, and $\tilde{d}$ is the optimal solution of the following quadratic problem

$$
\min (\hat{d}-d)^{\prime} \hat{\Sigma}_{d}^{-1}(\hat{d}-d) \quad \text { s.t. } d \geq 0_{q-1}
$$

Following the methods in Kan et al. (2013), we employ the asymptotic distribution of $L R$ and the corresponding $p$-value to perform statistical analysis 5

\section{Pricing models in our tests}

Our tests use both liquidity-risk-based and non-liquidity-risk-based pricing models. The following describes these models (we also investigate the capital asset pricing model, CAPM, but corresponding results are not reported):

(a) The non-liquidity-risk-based pricing models:

\footnotetext{
${ }^{5}$ The non-nested multiple model comparison involves a sequence selection process and the appendix in Kan et al.'s (2013) website shows the details.
} 
- The Fama and French (1993) three-factor model (FF3),

$$
E\left(R_{i}\right)=R_{f}+\beta_{i, M K T} E(M K T)+\beta_{i, S M B} E(S M B)+\beta_{i, H M L} E(H M L),
$$

where $E\left(R_{i}\right)$ is the expected rate of return of asset $i, R_{f}$ is the risk-free rate proxied by the one-month T-bill rate, $E(M K T)$ is the expected value of the market factor, $E(S M B)$ is the expected value of the Fama-French size factor, and $E(H M L)$ is the expected value of the book-to-market factor. The market factor is proxied by the excess return of the CRSP value-weighted NYSE/AMEX/ARCA/NASDAQ index, the size factor is the return difference between small stock portfolio and big stock portfolio, and the book-to-market factor is the return difference between high book-to-market ratio stocks and low book-to-market ratio stocks.

- The four-factor model of Carhart (1997) (C4),

$$
E\left(R_{i}\right)=R_{f}+\beta_{i, M K T} E(M K T)+\beta_{i, S M B} E(S M B)+\beta_{i, H M L} E(H M L)+\beta_{i, U M D} E(U M D),
$$

where $E(U M D)$ is the expected value of the momentum factor, which is constructed as the return difference between the past price winners and the past price losers.

- The Fama and French (2015) five-factor model (FF5),

$$
E\left(R_{i}\right)=R_{f}+\beta_{i, M K T} E(M K T)+\beta_{i, S M B^{*}} E\left(S M B^{*}\right)+\beta_{i, H M L} E(H M L)+\beta_{i, R M W} E(R M W)+\beta_{i, C M A} E(C M A),
$$

where $E(R M W)$ is the expected value of the profitability factor and $E(C M A)$ is the expected value of the investment factor. The profitability factor is the return difference between the high-profitability stocks and the low-profitability stocks, and the investment factor is the return difference between the low asset growth stocks and the high asset growth stocks. In addition, the size factor of the FF5 is constructed slightly different from the one of the FF3, and we label the size factor of the FF5 as $S M B^{*}$.

- The Hou, Xue, and Zhang (2015) four-factor model (HXZ4),

$$
E\left(R_{i}\right)=R_{f}+\beta_{i, M K T} E(M K T)+\beta_{i, M E} E(M E)+\beta_{i, I A} E(I A)+\beta_{i, R O E} E(R O E),
$$

where $M E, I A$ and $R O E$ are the size, investment and profitability factors of the HXZ4.

(b) The liquidity-risk-based pricing models:

- The Pástor and Stambaugh (2003) four-factor model (PS4 $\left.{ }_{t r d}\right)$,

$$
E\left(R_{i}\right)=R_{f}+\beta_{i, M K T} E(M K T)+\beta_{i, S M B} E(S M B)+\beta_{i, H M L} E(H M L)+\beta_{i, P S_{t r d}} E\left(P S_{t r d}\right),
$$


where $P S_{\text {trd }}$ is the PS traded liquidity factor. When assessing the premiums associated with the factor loadings and covariance risks, we also use the PS non-traded factor $\left(P S_{i n n}\right)$ with the corresponding model labeled as PS4 $4_{i n n}$. Pástor and Stambaugh (2003) construct the two factors using their price impact measure of liquidity.

- The Sadka (2006) two-factor model (S2), which we estimate it with monthly data by running the regression below:

$$
R_{i, t}-R_{f, t}=\alpha_{i}+\beta_{i, M K T} M K T_{t}+\beta_{i, S F} S F_{t}+\epsilon_{i, t},
$$

where $S F_{t}$ is the month- $t$ value of the Sadka (2006) liquidity factor, which is constructed based on the variable component of price impact ${ }^{6}$ The Sadka factor is non-traded. Sadka (2006) also extends the FF3 with his liquidity factor. To save place, we do not report the results of the Sadka (2006) liquidity factor extended FF3.

- The liquidity-augmented capital asset pricing model of Liu (2006) (LCAPM),

$$
E\left(R_{i}\right)=R_{f}+\beta_{i, M K T} E(M K T)+\beta_{i, L F} E(L F)
$$

where $L F$ is the Liu factor, which is constructed based on his trading-discontinuity measure of liquidity.

Table 1

Descriptive statistics.

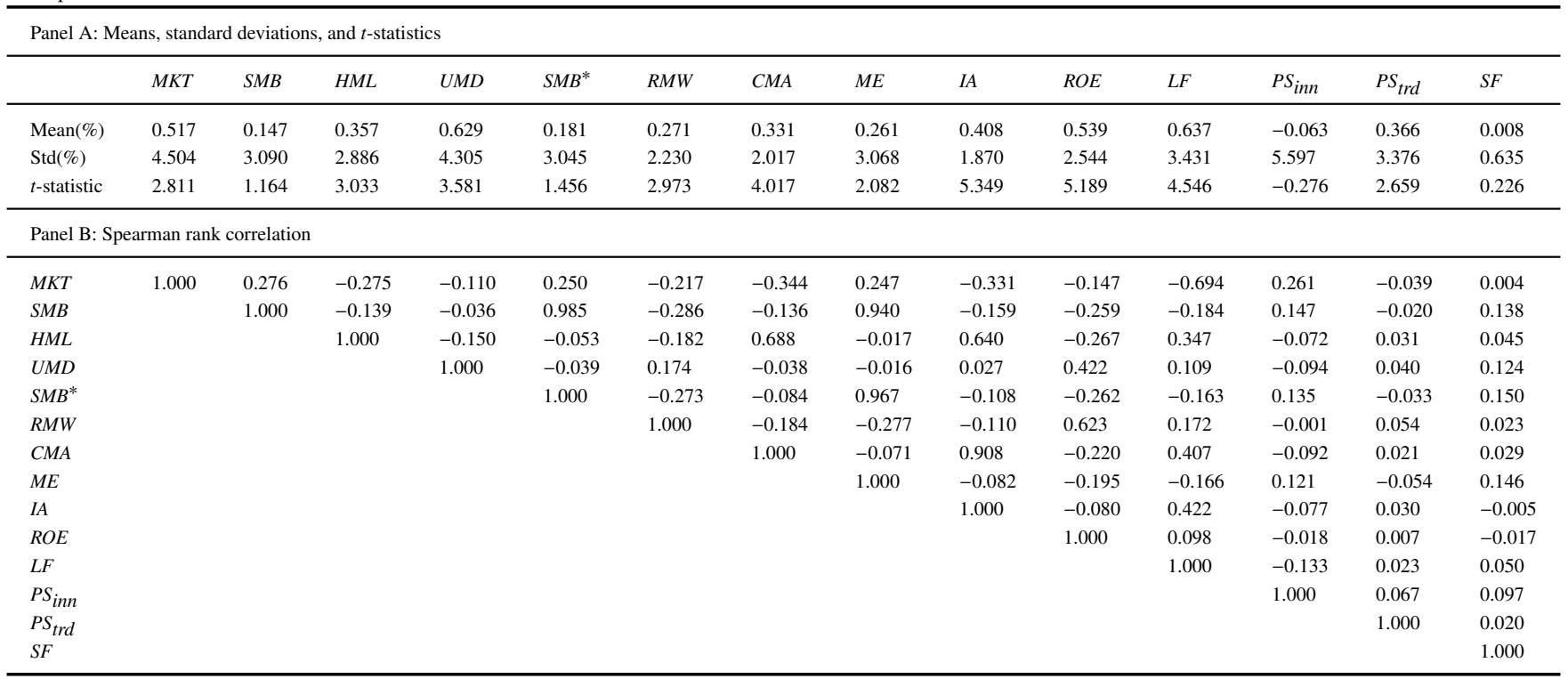

Table 1 reports summary statistics for the monthly factor values over the period $1 / 1968-12 / 2017$, but the sample period is from 4/1983-12/2012 if the Sadka (2006) factor is involved. Panel A shows that the factor means, which range from $-0.063 \%$ to $0.637 \%$, are generally significant except for the size factor $\left(S M B\right.$ and $\left.S M B^{*}\right)$ and the non-traded factors of $P S_{i n n}$ and $S F$. Panel B shows that the Hou, Xue, and Zhang (2015) size factor is highly correlated with the Fama-French size factor at 0.967 , similarly

\footnotetext{
${ }^{6}$ Sadka (2006) decomposes liquidity into variable and fixed components, and shows that it is the variable rather than the fixed component capturing the trading impact on price.
} 
between their investment factors at 0.908 and between their profitability factors at 0.623 . By inspecting the correlations of the four liquidity factors, there is virtually no correlation between each other, indicating that these liquidity factors capture different information. In addition, these four liquidity factors show limited correlations with the non-liquidity firm-characteristics-based factors. The highest correlation between the liquidity factor and the firm-characteristics-based factor is 0.422 between $L F$ and $I A$, implying that information captured by the liquidity factors and the non-liquidity factors is not the same.

\section{The pricing ability tests of factors}

This section examines the pricing ability of factor models following the testing procedure introduced by Kan et al. (2013). In the first subsection, we estimate the premium related to factor loadings/betas and covariance risk with the commonly used 25 size and book-to-market (25 ME-BE/ME) portfolios. For robustness, we also use the 25 size-momentum portfolios and the 32 size-investment-profitability portfolios $7^{7}$ These testing portfolios are clearly in favor of supporting the models containing the corresponding factors such as size, profitability, and investment factors. Based on these testing portfolios, it will be firm evidence to support the liquidity factors/models if they display comparable performance with those of characteristics-based factors/models.

\subsection{Results based on the 25 ME-BE/ME portfolios}

\subsubsection{The specification test of factor models}

Before conducting pricing tests, we first examine whether the selected models are correctly specified (denoted by $\left.R^{2}=1\right)$ based on the $R^{2}$ test and the $F$-test. Table 2 presents the specification test results for eight factor models under the $25 \mathrm{ME}$ BE/ME portfolios. For the OLS estimation in Panel A, the null hypothesis that the model being examined is correctly identified is rejected by both the $R^{2}$ test and the $F$-test at the $5 \%$ level of significance for nearly all models. The exceptions are $\mathrm{C} 4$ and $\mathrm{S} 2$, which can pass the $R^{2}$ test in the OLS case. The GLS test is more strict for evaluating pricing models, as argued by Lewellen et al. (2010). Panel B shows consistent evidence that the GLS $R^{2}$ of each model is lower than the corresponding OLS $R^{2}$ estimate. Also, all models are rejected for the null assumption under GLS as indicated by the approximately zero values of $p\left(R^{2}=1\right)$ and $p(Q=0)$. Overall, the specification test results indicate that all the eight models examined have the possibility of being misspecified. Therefore, it is necessary to perform statistical analysis under the assumption of misspecified models ${ }^{8}$

\footnotetext{
${ }^{7}$ We obtain the monthly returns of the testing portfolios from Kenneth French's website.

${ }^{8}$ We also conduct the specification tests using the 25 ME-Mom portfolios and the 32 ME-Inv-OP portfolios (results untabulated). For the 25 ME-Mom portfolios, only S2 with $R^{2}$ test, PS4 ${ }_{i n n}$ and FF5 with $F$-test pass the test when adopting the OLS method. Applying the 32 ME-Inv-OP portfolios, C4 can pass the null hypothesis test with both OLS and GLS methods, and S2 can not be rejected by the $R^{2}$ test from the OLS estimation.
} 


\begin{tabular}{|c|c|c|c|c|c|c|c|c|}
\hline & S2 & LCAPM & $\mathrm{PS}_{i n n}$ & $\mathrm{PS} 4_{t r d}$ & FF3 & $\mathrm{C} 4$ & FF5 & HXZ4 \\
\hline \multicolumn{9}{|c|}{ Panel A: OLS } \\
\hline$\hat{R}^{2}$ & 0.491 & 0.396 & 0.682 & 0.687 & 0.642 & 0.733 & 0.741 & 0.697 \\
\hline$\hat{Q}$ & 0.180 & 0.113 & 0.076 & 0.088 & 0.104 & 0.062 & 0.076 & 0.095 \\
\hline$p(Q=0)$ & 0.000 & 0.000 & 0.002 & 0.000 & 0.000 & 0.019 & 0.001 & 0.000 \\
\hline \multicolumn{9}{|c|}{ Panel B: GLS } \\
\hline$\hat{R}^{2}$ & 0.235 & 0.118 & 0.279 & 0.264 & 0.223 & 0.346 & 0.252 & 0.226 \\
\hline$p\left(R^{2}=1\right)$ & 0.000 & 0.000 & 0.001 & 0.000 & 0.000 & 0.005 & 0.000 & 0.000 \\
\hline$\hat{Q}$ & 0.175 & 0.117 & 0.078 & 0.094 & 0.103 & 0.076 & 0.088 & 0.095 \\
\hline$p(Q=0)$ & 0.000 & 0.000 & 0.002 & 0.000 & 0.000 & 0.002 & 0.000 & 0.000 \\
\hline
\end{tabular}

Note: This table reports results of testing whether a model is correctly specified using sample $R^{2}\left(\hat{R}^{2}\right)$ and $F$-test statistics $(\hat{Q})$. The test assets are the monthly returns on the 25 ME-BE/ME portfolios. The $p$-values of $p\left(R^{2}=1\right)$ and $p(Q=0)$ are for the null hypothesis that a model is correctly identified (i.e., $R^{2}=1$ or $Q=0$ ). We report both the OLS (Panel A) and GLS (Panel B) cross-sectional regression results. The symbol S2 stands for the Sadka (2006) two-factor model, PS4 trd for the FF3 extended by the PS traded liquidity factor, and PS4 $4_{i n n}$ for the FF3 extended by the PS non-traded liquidity factor.

\subsubsection{Risk premiums related to betas}

To test whether investors price the risk captured by a proposed factor, we investigate the premium associated with the loading (i.e., beta) on the factor. A significant premium implies that the factor risk is priced by the market. Table 3 presents the risk premium $(\gamma)$ estimates (see equations (3) and (4p) under both OLS and GLS methods. To make inferences, we use the misspecified $t$-ratio of Kan et al. (2013), $t_{K R S}$. For comparison, we also present Shanken (1992) $t$-ratio $\left(t_{S}\right)$ under the assumption of correct model specification. For the four liquidity factors examined, the OLS estimates in Panel A show that the tradingdiscontinuity-based liquidity risk factor of the LCAPM produces positive and statistically significant risk premium of $0.762 \%$ $\left(t_{K R S}=3.037\right)$. The evidence suggests that investors require a high return to compensate for bearing liquidity risk. In contrast, other liquidity factors (i.e., the two Pástor-Stambaugh factors of $P S_{i n n}$ and $P S_{t r d}$, and the Sadka factor of $S F$ ) show weak pricing ability because the corresponding risk premium estimates are statistically insignificant at the conventional level based on both $t_{S}$ and $t_{K R S}$. For the non-liquidity factors examined, factor risk premium estimates associated with $H M L, M E, R M W$ and $I A$ are positive and statistically significant at the $5 \%$ level of significance. However, risks related to $S M B, S M B^{*}, C M A$ and $R O E$ are not priced because the associated premium estimates are insignificant. Among all factors, the misspecified model assumption shows obvious effect on the momentum factor, $U M D$. While the loading on $U M D$ shows significant premium with the $t_{S}$ of 3.58 , the misspecified-robust $t_{K R S}$ of 1.5 indicates insignificant pricing power of $U M D$. The large difference between $t_{S}$ and $t_{K R S}$ suggests that $U M D$ has low correlation with the returns of test assets $9^{9}$ Consistent with early studies (e.g., Kan et al., 2013; Jagannathan and Wang, 1996; Petkova, 2006), we find that the loading on the market factor MKT is negatively related to expected return in most model specifications (except for C4). The GLS estimates presented in Table 3, Panel B, largely mirror the OLS results of Panel A with exceptions associated with $M E$ and $R M W$, which turn to be insignificant to predict returns.

\footnotetext{
${ }^{9}$ According to Kan et al. (2013), for factors that have low correlation with test assets, the $t_{K R S}$ of $\gamma$ has an obvious change in comparison with $t_{S}$.
} 
Table 3

Beta risk premium estimates based on the $25 \mathrm{ME}-\mathrm{BE} / \mathrm{ME}$ portfolios.

\begin{tabular}{|c|c|c|c|c|c|c|c|c|c|c|c|c|c|c|c|}
\hline Models & $\hat{\gamma}_{0}$ & $\hat{\gamma}_{M K T}$ & $\hat{\gamma}_{S M B}$ & $\hat{\gamma}_{S M B^{*}}$ & $\hat{\gamma}_{H M L}$ & $\hat{\gamma}_{U M D}$ & $\hat{\gamma}_{R M W}$ & $\hat{\gamma}_{C M A}$ & $\hat{\gamma}_{M E}$ & $\hat{\gamma}_{I A}$ & $\hat{\gamma}_{R O E}$ & $\hat{\gamma}_{L F}$ & $\hat{\gamma}_{P S_{i n n}}$ & $\hat{\gamma}_{P S}{ }_{t r d}$ & $\hat{\gamma}_{S F}$ \\
\hline \multicolumn{16}{|c|}{ Panel A: OLS } \\
\hline LCAPM & $\begin{array}{l}1.405 \\
(2.134) \\
\end{array}$ & $\begin{array}{l}-0.334 \\
(-0.664) \\
{[-0.649]}\end{array}$ & & & & & & & & & & $\begin{array}{l}0.762 \\
(3.114) \\
\end{array}$ & & & \\
\hline $\mathrm{PS}_{t r d}$ & $\begin{array}{l}1.470 \\
(3.540) \\
{[3.276]}\end{array}$ & $\begin{array}{l}-0.568 \\
(-1.596) \\
{[-1.479]}\end{array}$ & $\begin{array}{l}0.118 \\
(0.921) \\
{[0.908]}\end{array}$ & & $\begin{array}{l}0.134 \\
(2.993) \\
{[3.021]}\end{array}$ & & & & & & & & & $\begin{array}{l}1.628 \\
(1.812) \\
{[1.419]}\end{array}$ & \\
\hline S2 & $\begin{array}{l}2.014 \\
(2.510) \\
{[2.253]}\end{array}$ & $\begin{array}{l}{[-0.979]} \\
(-1.451) \\
{[-1.325]}\end{array}$ & & & & & & & & & & & & & $\begin{array}{l}0.222 \\
(1.161) \\
{[1.019]}\end{array}$ \\
\hline FF3 & $\begin{array}{l}1.621 \\
(4.512) \\
{[4.210]}\end{array}$ & $\begin{array}{l}-0.678 \\
(-2.062) \\
{[-1.935]}\end{array}$ & $\begin{array}{l}0.090 \\
(0.696) \\
{[0.700]}\end{array}$ & & $\begin{array}{l}0.368 \\
(3.036) \\
{[3.025]}\end{array}$ & & & & & & & & & & \\
\hline C4 & $\begin{array}{l}0.803 \\
(1.093)\end{array}$ & $\begin{array}{l}0.171 \\
(0.403)\end{array}$ & $\begin{array}{l}0.106 \\
(0.812)\end{array}$ & & $\begin{array}{l}0.404 \\
(3.284)\end{array}$ & $\begin{array}{l}2.583 \\
(3.580)\end{array}$ & & & & & & & & & \\
\hline FF5 & $\begin{array}{l}{[0.630]} \\
1.409 \\
(3.281) \\
{[2.848]}\end{array}$ & $\begin{array}{l}{[0.248]} \\
-0.519 \\
(-1.435) \\
{[-1.286]}\end{array}$ & {$[0.785]$} & $\begin{array}{l}0.227 \\
(1.785) \\
{[1.786]}\end{array}$ & $\begin{array}{l}{[3.364]} \\
0.329 \\
(2.732) \\
{[2.668]}\end{array}$ & {$[1.500]$} & $\begin{array}{l}0.504 \\
(2.829) \\
{[2.146]}\end{array}$ & $\begin{array}{l}-0.093 \\
(-0.474) \\
{[-0.378]}\end{array}$ & & & & & & & \\
\hline HXZ4 & $\begin{array}{l}1.056 \\
(2.704) \\
{[2.452]}\end{array}$ & $\begin{array}{l}-0.358 \\
(-0.969) \\
{[-0.898]}\end{array}$ & & & & & & & $\begin{array}{l}0.274 \\
(2.019) \\
{[1.980]}\end{array}$ & $\begin{array}{l}0.377 \\
(3.161) \\
{[3.203]}\end{array}$ & $\begin{array}{l}0.411 \\
(1.861) \\
{[1.825]}\end{array}$ & & & & \\
\hline \multicolumn{16}{|c|}{ Panel B: GLS } \\
\hline $\mathrm{PS}_{i n n}$ & $\begin{array}{l}1.800 \\
(5.529) \\
{[4.870]}\end{array}$ & $\begin{array}{l}-0.860 \\
(-2.731) \\
{[-2.479]}\end{array}$ & $\begin{array}{l}0.147 \\
(1.162) \\
{[1.159]}\end{array}$ & & $\begin{array}{l}0.332 \\
(2.776) \\
{[2.751]}\end{array}$ & & & & & & & & $\begin{array}{l}1.491 \\
(1.641) \\
{[1.090]}\end{array}$ & & \\
\hline $\mathrm{PS}_{t r d}$ & $\begin{array}{l}1.687 \\
(4.999) \\
{[4.358]}\end{array}$ & $\begin{array}{l}-0.766 \\
(-2.415) \\
{[-2.157]}\end{array}$ & $\begin{array}{l}0.151 \\
(1.190) \\
{[1.192]}\end{array}$ & & $\begin{array}{l}0.347 \\
(2.906) \\
{[2.897]}\end{array}$ & & & & & & & & & $\begin{array}{l}1.060 \\
(1.797) \\
{[1.159]}\end{array}$ & \\
\hline S2 & $\begin{array}{l}2.362 \\
(7.563) \\
{[6.585]}\end{array}$ & $\begin{array}{l}-1.372 \\
(-3.889) \\
{[-3.485]}\end{array}$ & & & & & & & & & & & & & $\begin{array}{l}0.198 \\
(1.900) \\
{[1.213]}\end{array}$ \\
\hline FF3 & $\begin{array}{l}1.797 \\
(5.817)\end{array}$ & $\begin{array}{l}-0.865 \\
(-2.843)\end{array}$ & $\begin{array}{l}0.150 \\
(1.182)\end{array}$ & & $\begin{array}{l}0.339 \\
(2.841)\end{array}$ & & & & & & & & & & \\
\hline C4 & $\begin{array}{l}{[5.246]} \\
1.328 \\
(3.072)\end{array}$ & $\begin{array}{l}{[-2.2632]} \\
-0.381 \\
(-1.063)\end{array}$ & $\begin{array}{l}{[1.184]} \\
0.152 \\
(1.197)\end{array}$ & & $\begin{array}{l}{[2.826]} \\
0.349 \\
(2.920)\end{array}$ & $\begin{array}{l}1.755 \\
(3.018)\end{array}$ & & & & & & & & & \\
\hline FF5 & $\begin{array}{l}{[2.311]} \\
1.666 \\
(4.844)\end{array}$ & $\begin{array}{l}{[-0.834]} \\
-0.749 \\
(-2.336)\end{array}$ & {$[1.196]$} & $\begin{array}{l}0.195 \\
(1.550)\end{array}$ & $\begin{array}{l}{[2.913]} \\
0.341 \\
(2.857) \\
0.817]\end{array}$ & {$[1.885]$} & $\begin{array}{l}0.272 \\
(1.773)\end{array}$ & $\begin{array}{l}0.177 \\
(1.007)\end{array}$ & & & & & & & \\
\hline HXZ4 & $\begin{array}{l}{[4.111]} \\
1.716 \\
(4.936) \\
{[4.247]}\end{array}$ & $\begin{array}{l}{[-2.060]} \\
-0.800 \\
(-2.465) \\
{[-2.203]}\end{array}$ & & {$[1.557]$} & {$[2.817]$} & & [1.293] & {$[0.731]$} & $\begin{array}{l}0.248 \\
(1.867) \\
{[1.827]}\end{array}$ & $\begin{array}{l}0.249 \\
(2.232) \\
{[2.112]}\end{array}$ & $\begin{array}{l}0.287 \\
(1.497) \\
{[1.336]}\end{array}$ & & & & \\
\hline
\end{tabular}

Note: Based on the $25 \mathrm{ME}-\mathrm{BE} / \mathrm{ME}$ portfolios, this table presents the risk premium estimates associated with the factor loadings (betas) for eight pricing models. The reported $\hat{\gamma}$ estimates are in percentage. Numbers in parentheses are the Shanken (1992) $t$-ratios $\left.t_{S}\right)$ under correct model specification, and numbers in square brackets are the misspecificationrobust $t$-ratios of Kan et al. (2013) $\left(t_{K R S}\right)$. The $t$-ratio of $\hat{\gamma}_{0}$ is to examine the null hypothesis that the zero-beta rate is equal to zero.

Table 4

Covariance risk price estimates based on the $25 \mathrm{ME}-\mathrm{BE} / \mathrm{ME}$ portfolios.

\begin{tabular}{|c|c|c|c|c|c|c|c|c|c|c|c|c|c|c|c|}
\hline Models & $\hat{\lambda}_{0}$ & $\hat{\lambda}_{M K T}$ & $\hat{\lambda}_{S M B}$ & $\hat{\lambda}_{S M B^{*}}$ & $\hat{\lambda}_{H M L}$ & $\hat{\lambda}_{U M D}$ & $\hat{\lambda}_{R M W}$ & $\hat{\lambda}_{C M A}$ & $\hat{\lambda}_{M E}$ & $\hat{\lambda}_{I A}$ & $\hat{\lambda}_{R O E}$ & $\hat{\lambda}_{L F}$ & $\hat{\lambda}_{P S_{i n n}}$ & $\hat{\lambda}_{P S_{t r d}}$ & $\hat{\lambda}_{S F}$ \\
\hline \multicolumn{16}{|c|}{ Panel A: OLS } \\
\hline LCAPM & $\begin{array}{l}0.014 \\
(2.134) \\
{[2.051]}\end{array}$ & $\begin{array}{l}2.950 \\
(0.685) \\
{[0.673]}\end{array}$ & & & & & & & & & & $\begin{array}{l}9.064 \\
(1.989) \\
{[1.970]}\end{array}$ & & & \\
\hline $\mathrm{PS}_{i n n}$ & $\begin{array}{l}0.015 \\
(3.949) \\
{[3.526]}\end{array}$ & $\begin{array}{l}-5.798 \\
(-2.259) \\
{[-1.822]}\end{array}$ & $\begin{array}{l}2.458 \\
(1.438) \\
{[1.263]}\end{array}$ & & $\begin{array}{l}3.459 \\
(1.947) \\
{[1.688]}\end{array}$ & & & & & & & & $\begin{array}{l}7.582 \\
(1.767) \\
{[1.348]}\end{array}$ & & \\
\hline $\mathrm{PS}_{t r d}$ & $\begin{array}{l}0.015 \\
0.540) \\
{[3.276]}\end{array}$ & $\begin{array}{l}-2.695 \\
(-1.304) \\
{[-1.163]}\end{array}$ & $\begin{array}{l}2.952 \\
(1.722) \\
{[1.679]}\end{array}$ & & $\begin{array}{l}3.080 \\
(1.680) \\
{[1.571]}\end{array}$ & & & & & & & & & $\begin{array}{l}14.138 \\
(1.777) \\
{[1.375]}\end{array}$ & \\
\hline S2 & $\begin{array}{l}0.020 \\
(2.510) \\
{[2.253]}\end{array}$ & $\begin{array}{l}-5.994 \\
(-1.952) \\
{[-1.869]}\end{array}$ & & & & & & & & & & & & & $\begin{array}{l}61.304 \\
(1.298 \\
11.125\end{array}$ \\
\hline FF3 & $\begin{array}{l}0.016 \\
(4.512) \\
{[4.210]}\end{array}$ & $\begin{array}{l}-3.299 \\
(-1.785) \\
{[-1.680]}\end{array}$ & $\begin{array}{l}2.996 \\
(1.928) \\
{[1.934]}\end{array}$ & & $\begin{array}{l}3.638 \\
(2.192) \\
{[2.156]}\end{array}$ & & & & & & & & & & \\
\hline $\mathrm{C} 4$ & $\begin{array}{l}0.008 \\
(1.093)\end{array}$ & $\begin{array}{l}4.696 \\
(1.553)\end{array}$ & $\begin{array}{l}1.881 \\
(0.997)\end{array}$ & & $\begin{array}{l}11.635 \\
(3.929)\end{array}$ & $\begin{array}{l}16.113 \\
(3.551)\end{array}$ & & & & & & & & & \\
\hline FF5 & $\begin{array}{l}{[0.630]} \\
0.014 \\
3.281) \\
{[2.848]}\end{array}$ & $\begin{array}{l}{[0.816]} \\
-3.279 \\
(-1.252) \\
{[-1.075]}\end{array}$ & {$[0.890]$} & $\begin{array}{l}6.599 \\
(3.465) \\
{[3.282]}\end{array}$ & $\begin{array}{l}{[2.139]} \\
8.896 \\
(1.815) \\
{[1.355]}\end{array}$ & [1.564] & $\begin{array}{l}10.847 \\
(2.504) \\
{[1.923]}\end{array}$ & $\begin{array}{l}-13.236 \\
(-1.273) \\
{[-0.987]}\end{array}$ & & & & & & & \\
\hline HXZ4 & $\begin{array}{l}0.013 \\
(2.704) \\
{[2.452]}\end{array}$ & $\begin{array}{l}-0.062 \\
(-0.024) \\
{[-0.022]}\end{array}$ & & & & & & & $\begin{array}{l}6.039 \\
(3.006) \\
{[3.014]}\end{array}$ & $\begin{array}{l}11.520 \\
(2.364) \\
{[2.220]}\end{array}$ & $\begin{array}{l}8.310 \\
(1.976) \\
{[1.859]}\end{array}$ & & & & \\
\hline \multicolumn{16}{|c|}{ Panel B: GLS } \\
\hline $\mathrm{PS}_{i n n}$ & $\begin{array}{l}0.018 \\
(5.529) \\
{[4.870]}\end{array}$ & $\begin{array}{l}-7.077 \\
(-3.192) \\
{[-2.517]}\end{array}$ & $\begin{array}{l}3.552 \\
(2.194) \\
{[1.968]}\end{array}$ & & $\begin{array}{l}2.861 \\
(1.662) \\
{[1.465]}\end{array}$ & & & & & & & & $\begin{array}{l}6.508 \\
(2.004) \\
{[1.310]}\end{array}$ & & \\
\hline $\mathrm{PS}_{t r d}$ & $\begin{array}{l}0.017 \\
(4.999) \\
{[4.358]}\end{array}$ & $\begin{array}{l}-3.937 \\
(-2.165) \\
{[-1.862]}\end{array}$ & $\begin{array}{l}11.756 \\
(2.363) \\
{[2.283]}\end{array}$ & & $\begin{array}{l}1.744 \\
(1.635) \\
{[1.603]}\end{array}$ & & & & & & & & & $\begin{array}{l}9.136 \\
(1.748) \\
{[1.127]}\end{array}$ & \\
\hline S2 & $\begin{array}{l}0.024 \\
(7.563) \\
{[6.585]}\end{array}$ & $\begin{array}{l}-7.829 \\
(-4.050) \\
{[-3.647]}\end{array}$ & & & & & & & & & & & & & $\begin{array}{l}57.123 \\
(2.128 \\
{[1.350}\end{array}$ \\
\hline FF3 & $\begin{array}{l}0.018 \\
(5.817) \\
{[5.246}\end{array}$ & $\begin{array}{l}-4.544 \\
(-2.643) \\
{[-2.441]}\end{array}$ & $\begin{array}{l}4.022 \\
(2.641) \\
{[2.570]}\end{array}$ & & $\begin{array}{l}2.974 \\
(1.820) \\
{[1.809]}\end{array}$ & & & & & & & & & & \\
\hline C4 & $\begin{array}{l}0.013 \\
(3.072) \\
{[2.311]}\end{array}$ & $\begin{array}{l}0.271 \\
(0.110) \\
0.077]\end{array}$ & $\begin{array}{l}3.320 \\
(2.014) \\
{[1.882]}\end{array}$ & & $\begin{array}{l}7.873 \\
(3.230) \\
{[2.296]}\end{array}$ & $\begin{array}{l}10.551 \\
(2.918) \\
{[1.879]}\end{array}$ & & & & & & & & & \\
\hline FF5 & $\begin{array}{l}0.017 \\
(4.844)\end{array}$ & $\begin{array}{l}-3.639 \\
(-1.617)\end{array}$ & & $\begin{array}{l}5.331 \\
(2.971)\end{array}$ & $\begin{array}{l}3.293 \\
(0.760)\end{array}$ & & $\begin{array}{l}6.061 \\
(1.710)\end{array}$ & $\begin{array}{l}-1.463 \\
(-0.161)\end{array}$ & & & & & & & \\
\hline HXZ4 & $\begin{array}{l}{[4.111]} \\
0.017 \\
(4.936) \\
{[4.247]}\end{array}$ & $\begin{array}{l}{[-1.319]} \\
-3.624 \\
(-1.676) \\
{[-1.470]}\end{array}$ & & {$[2.744]$} & {$[0.539]$} & & {$[1.341]$} & {$[-0.113]$} & $\begin{array}{l}5.771 \\
(3.073) \\
{[2.968]}\end{array}$ & $\begin{array}{l}4.731 \\
(1.106) \\
{[1.006]}\end{array}$ & $\begin{array}{l}5.215 \\
(1.455) \\
{[1.276]}\end{array}$ & & & & \\
\hline
\end{tabular}

Note: Based on the $25 \mathrm{ME}-\mathrm{BE} / \mathrm{ME}$ portfolios, this table presents the covariance risk price estimates $(\hat{\lambda})$ for the factors of the eight models. Numbers in parentheses are the Shanken (1992) $t$-ratios $\left(t_{S}\right)$ under correct model specification, and numbers in square brackets are the misspecification-robust $t$-ratios of Kan et al. (2013) $\left(t_{K R S}\right)$. 


\subsubsection{The covariance risk price estimates using the $25 \mathrm{ME}-B E / M E$ portfolios}

According to Kan et al. (2013), to examine a factor's ability in improving models' explanatory power, one can test whether the covariance risk price $(\lambda)$ associated with the factor of interest is statistically significant, see equations (7) and (8). Table 4 reports the covariance risk prices for all the 14 factors examined. The OLS results in Panel A show that the factors that contribute to models' explanation power are $H M L$ (in FF3 and C4), $S M B^{*}, M E, I A$, and $L F$, as indicated by their significant covariance risk prices based on misspecification-robust $t$-ratios, $t_{K R S}$. The significance of the covariance risk prices associated with $U M D, R M W$, and $R O E$ is sensitive to the test assumptions. It appears that the three factors improve the models' explanatory power based on the Shanken (1992) $t$-ratio, but they fail to add significant power to the models' return explanation based on the misspecification-robust $t$-ratios of Kan et al. (2013), $t_{K R S}$. All the remaining factors generate insignificant covariance risk prices, indicating that they have limited contribution to explain asset returns. With the GLS estimates of Panel B, the $t_{K R S}$ statistic reveals that the size factor $\left(S M B^{*}\right.$ and $\left.M E\right)$ is the only one resulting in the significant covariance risk price estimate at the 5\% level. The results are somewhat inconsistent with the empirical observation that the size premium disappears in the recent years. We will perform a sub-period analysis later.

\subsection{Tests with alternative portfolios}

Statistical inferences drawn from pricing model tests are sensitive to the choice of testing asset portfolios. For instance, Fama and French (2015) find that adding the momentum factor to the FF3 produces trivial change in model performance except when the testing portfolios are formed on momentum. As a result, we further test the beta risk premium and the covariance risk premium using two alternative sets of testing portfolios: the 25 size-momentum (ME-Mom) portfolios and the 32 sizeinvestment-profitability (ME-Inv-OP) portfolios.

\subsubsection{The testing results based on the $25 \mathrm{ME}-$ Mom portfolios}

Tables 5 and 6 present the factor risk premium and covariance risk price estimated based on the 25 ME-Mom portfolios. Similar to the results from the 25 ME-BE/ME portfolios, Table 5 shows that among the four liquidity factors, only the one of the LCAPM (18) shows significant pricing ability with the $\gamma$ estimates at $0.913 \%\left(t_{K R S}=3.94\right)$ and $0.436 \%\left(t_{K R S}=2.466\right)$ under the OLS and GLS methods. By inspecting the covariance risk price estimates reported in Table 6, the liquidity risk factor of the LCAPM (18) also yields significant $\lambda$ estimates with both OLS and GLS at $12.964\left(t_{K R S}=2.49\right)$ and $7.416\left(t_{S}=2.353\right)$. Based on the $t_{K R S}$ statistics, the PS and Sadka factors again show no significant covariance risk price estimates. The insignificant estimates of $\gamma$ and $\lambda$ associated with the PS and Sadka factors are consistent with other studies. Also, in line with Fama and French (2015), the momentum factor $U M D$ shows significant pricing power against the 25 size-momentum portfolios. Moreover, both the beta risk premium and covariance risk price estimates related to $R O E$ are statistically significant, coinciding with the 
argument of Hou et al. (2017) that $R O E$ helps to explain the momentum effect. Finally, the rest of the factors such as $S M B$, $H M L, R M W$, and $I A$ exhibit less robust pricing power.

\subsubsection{The testing results based on the $32 \mathrm{ME}-\mathrm{Inv}$-OP portfolios}

Based on the 32 portfolios formed on size, investment and profitability, we estimate the beta premium $\gamma$ and the covariance risk price $\lambda$ for each of the eight pricing models. These testing portfolios could provide supportive evidence to find significant estimates of the beta risk premium and covariance risk price associated with the investment and profitability factors. Results in

Tables 7 and 8 show that it is indeed the case. The factors of $C M A, I A, R M W$ and ROE perform well against these ME-Inv-OP portfolios and yield significant estimates of beta risk premium $(\gamma)$ and covariance risk price $(\lambda)$. For the liquidity factors, the $L F$ of the LCAPM (18) again is the only one that shows statistically significant $\gamma$ and $\lambda$ estimates. In addition, the market factor $M K T$ and the size factor $S M B$ show insignificant pricing ability, and the $\gamma$ and $\lambda$ estimates related to $U M D$ and $H M L$ (except for FF5) are significant against these 32 testing portfolios.

\subsubsection{Excess return analysis}

In this subsection, we impose the theoretical restriction that the zero-beta rate is equal to the risk-free rate. Specifically, for each factor model, we estimate beta risk premium $(\gamma)$ and covariance risk price $(\lambda)$ with the following equations:

$$
\begin{gathered}
E\left(R_{i}-R_{f}\right)=\sum_{k=1}^{K} \beta_{i, k} \gamma_{k}, \\
E\left(R_{i}-R_{f}\right)=\sum_{k=1}^{K} \operatorname{cov}\left(R_{i}, f_{k}\right) \lambda_{k} .
\end{gathered}
$$

Similar to the above evidence, untabulated results show that among the four liquidity factors, only the LCAPM-based liquidity risk premiums are statistically significant under the three sets of portfolios. The momentum factor $U M D$ also shows significant pricing ability among the non-liquidity risk factors. In addition, with excess returns on the left-hand side, the $\gamma$ and $\lambda$ estimates associated with the market factor $M K T$ are positive and statistically significant in some model specifications, in line with the evidence of Kan et al. (2013).

Our results so far reveal that the price-impact-based liquidity factors of Pástor and Stambaugh (2003) and Sadka (2006) generate insignificant liquidity risk premium, in line with early studies of Fama and French (2015, 2016), and Hou et al. (2017). The possible reason is that the price impact, which captures one of the multidimensions of liquidity, is inaccurate to proxy for liquidity and fails to produce a robust liquidity premium, as Pástor and Stambaugh (2003) and Ben-Rephael et al. (2015) showed. Consistent with our conjecture that different liquidity factors constructed with different liquidity measures can perform differently, the liquidity risk factor of the LCAPM [18), which is constructed with the trading-discontinuity-based measure that 
Table 5

Risk premium estimates based on the 25 ME-Mom portfolios.

\begin{tabular}{|c|c|c|c|c|c|c|c|c|c|c|c|c|c|c|c|}
\hline Models & $\hat{\gamma}_{0}$ & $\hat{\gamma}_{M K T}$ & $\hat{\gamma}_{S M B}$ & $\hat{\gamma}_{S M B^{*}}$ & $\hat{\gamma}_{H M L}$ & $\hat{\gamma}_{U M D}$ & $\hat{\gamma}_{R M W}$ & $\hat{\gamma}_{C M A}$ & $\hat{\gamma}_{M E}$ & $\hat{\gamma}_{I A}$ & $\hat{\gamma}_{R O E}$ & $\hat{\gamma}_{L F}$ & $\hat{\gamma}_{P S_{i n n}}$ & $\hat{\gamma}_{P S_{t r d}}$ & $\hat{\gamma}_{S F}$ \\
\hline \multicolumn{16}{|c|}{ Panel A: OLS } \\
\hline LCAPM & $\begin{array}{l}1.174 \\
(1.842) \\
{[1.380]}\end{array}$ & $\begin{array}{l}-0.128 \\
(-0.272) \\
{[-0.221]}\end{array}$ & & & & & & & & & & $\begin{array}{l}0.913 \\
(3.732) \\
{[3.940]}\end{array}$ & & & \\
\hline $\mathrm{PS}_{i n n}$ & $\begin{array}{l}2.686 \\
(3.660) \\
{[2.551]}\end{array}$ & $\begin{array}{l}-1.493 \\
(-2.462) \\
{[-1.727]}\end{array}$ & $\begin{array}{l}0.354 \\
(2.236) \\
{[1.870]}\end{array}$ & & $\begin{array}{l}-1.130 \\
(-2.597) \\
{[-1.821]}\end{array}$ & & & & & & & & $\begin{array}{l}4.499 \\
(3.222) \\
{[1.320]}\end{array}$ & & \\
\hline $\mathrm{PS}_{t r d}$ & $\begin{array}{l}2.754 \\
(4.678) \\
{[3.758]}\end{array}$ & $\begin{array}{l}-1.578 \\
(-3.145) \\
{[-2.510]}\end{array}$ & $\begin{array}{l}0.284 \\
(1.990) \\
{[1.991]}\end{array}$ & & $\begin{array}{l}-0.755 \\
(-2.485) \\
{[-2.275]}\end{array}$ & & & & & & & & & $\begin{array}{l}-0.833 \\
(-1.074) \\
{[-0.343]}\end{array}$ & \\
\hline S2 & $\begin{array}{l}1.353 \\
(2.418) \\
{[1.955]}\end{array}$ & $\begin{array}{l}-0.329 \\
(-0.689) \\
{[-0.583]}\end{array}$ & & & & & & & & & & & & & $\begin{array}{l}0.330 \\
(1.647) \\
{[1.622]}\end{array}$ \\
\hline FF3 & $\begin{array}{l}2.832 \\
(5.057) \\
(44411\end{array}$ & $\begin{array}{l}-1.652 \\
(-3.426) \\
\end{array}$ & $\begin{array}{l}0.270 \\
(1.891)\end{array}$ & & $\begin{array}{l}-0.755 \\
(-2.518) \\
(-2.291)\end{array}$ & & & & & & & & & & \\
\hline C4 & $\begin{array}{l}0.515 \\
(0.233) \\
{[0.155}\end{array}$ & $\begin{array}{l}0.455 \\
(0.850) \\
{[0.606]}\end{array}$ & $\begin{array}{l}0.072 \\
(0.477) \\
{[0.408}\end{array}$ & & $\begin{array}{l}0.591 \\
(1.698) \\
{[1.100]}\end{array}$ & $\begin{array}{l}0.717 \\
(4.006) \\
{[3.944]}\end{array}$ & & & & & & & & & \\
\hline FF5 & $\begin{array}{l}0.475 \\
(0.151) \\
{[0.135]}\end{array}$ & $\begin{array}{l}0.091 \\
0.882) \\
{[0.799]}\end{array}$ & & $\begin{array}{l}0.349 \\
(2.375) \\
{[2.258]}\end{array}$ & $\begin{array}{l}-0.379 \\
(-0.994) \\
{[-0.696]}\end{array}$ & & $\begin{array}{l}0.226 \\
(0.649) \\
{[0.393]}\end{array}$ & $\begin{array}{l}0.984 \\
(2.651) \\
{[1.582]}\end{array}$ & & & & & & & \\
\hline HXZ4 & $\begin{array}{l}0.448 \\
(0.114) \\
{[0.086]}\end{array}$ & $\begin{array}{l}0.457 \\
(0.903) \\
{[0.727]}\end{array}$ & & & & & & & $\begin{array}{l}0.414 \\
(2.967) \\
{[2.828]}\end{array}$ & $\begin{array}{l}0.186 \\
(0.719) \\
{[0.585]}\end{array}$ & $\begin{array}{l}0.666 \\
{[3.759)} \\
{[2.870]}\end{array}$ & & & & \\
\hline \multicolumn{16}{|c|}{ Panel B: GLS } \\
\hline LCAPM & $\begin{array}{l}0.902 \\
(1.791) \\
{[1.319]}\end{array}$ & $\begin{array}{l}0.097 \\
(0.287) \\
{[0.222]}\end{array}$ & & & & & & & & & & $\begin{array}{l}0.436 \\
(2.523) \\
{[2.466]}\end{array}$ & & & \\
\hline $\mathrm{PS}_{\text {inn }}$ & $\begin{array}{l}2.070 \\
(4.987) \\
{[3.485]}\end{array}$ & $\begin{array}{l}-1.044 \\
(-2.820) \\
{[-2.067]}\end{array}$ & $\begin{array}{l}0.388 \\
(2.768) \\
{[2.609]}\end{array}$ & & $\begin{array}{l}-0.574 \\
(-2.205) \\
{[-1.536]}\end{array}$ & & & & & & & & $\begin{array}{l}1.665 \\
(1.901) \\
{[1.053]}\end{array}$ & & \\
\hline $\mathrm{PS}_{\text {trd }}$ & $\begin{array}{l}1.909 \\
(4.861) \\
{[3.318]}\end{array}$ & $\begin{array}{l}-0.902 \\
(-2.572) \\
{[-1.872]}\end{array}$ & $\begin{array}{l}0.341 \\
(2.488) \\
{[2.431]}\end{array}$ & & $\begin{array}{l}-0.347 \\
(-1.524) \\
{[-1.191]}\end{array}$ & & & & & & & & & $\begin{array}{l}-0.456 \\
(-0.788) \\
{[-0.450]}\end{array}$ & \\
\hline S2 & $\begin{array}{l}1.282 \\
(3.697) \\
{[3.295]}\end{array}$ & $\begin{array}{l}-0.288 \\
(-0.859) \\
{[-0.808]}\end{array}$ & & & & & & & & & & & & & $\begin{array}{l}-0.076 \\
(-0.865) \\
{[-0.608]}\end{array}$ \\
\hline FF3 & $\begin{array}{l}1.951 \\
(5.105) \\
{[3.516]}\end{array}$ & $\begin{array}{l}-0.942 \\
(-2.728) \\
{[-2.005]}\end{array}$ & $\begin{array}{l}0.338 \\
(2.474) \\
{[2.397]}\end{array}$ & & $\begin{array}{l}-0.352 \\
(-1.549) \\
{[-1.200]}\end{array}$ & & & & & & & & & & \\
\hline $\mathrm{C} 4$ & $\begin{array}{l}1.344 \\
(2.519) \\
{[1.547]}\end{array}$ & $\begin{array}{l}-0.370 \\
(-0.916) \\
{[-0.600]}\end{array}$ & $\begin{array}{l}0.260 \\
(1.868) \\
{[1.651]}\end{array}$ & & $\begin{array}{l}0.052 \\
(0.190) \\
{[0.121]}\end{array}$ & $\begin{array}{l}0.653 \\
(3.682) \\
{[3.622]}\end{array}$ & & & & & & & & & \\
\hline FF5 & $\begin{array}{l}1.547] \\
1.351 \\
(2.515)\end{array}$ & $\begin{array}{l}{[-0.600]} \\
-0.382 \\
(-0.940)\end{array}$ & {$[1.651]$} & $\begin{array}{l}0.372 \\
(2.691)\end{array}$ & $\begin{array}{l}{[0.121]} \\
-0.542 \\
(-1.842)\end{array}$ & [3.622] & $\begin{array}{l}0.291 \\
(1.098) \\
(0.731\end{array}$ & $\begin{array}{l}0.556 \\
(1.923)\end{array}$ & & & & & & & \\
\hline HXZ4 & $\begin{array}{l}{[1.892]} \\
0.765 \\
(1.101) \\
{[0.805]}\end{array}$ & $\begin{array}{l}{[-0.727]} \\
0.140 \\
(0.376) \\
{[0.293]}\end{array}$ & & [2.754] & {$[-1.513]$} & & {$[0.731]$} & [1.396] & $\begin{array}{l}0.409 \\
(2.994) \\
{[2.953]}\end{array}$ & $\begin{array}{l}0.208 \\
(1.118) \\
{[0.832]}\end{array}$ & $\begin{array}{l}0.677 \\
(4.073) \\
{[3.213]}\end{array}$ & & & & \\
\hline
\end{tabular}

Note: This table presents the risk premium estimates based on the 25 ME-Mom portfolios for eight pricing models. We report parameter estimates $\hat{\gamma}(\%)$, the Shanken (1992) $t$-ratio under correctly specified models ( $t_{S}$ in parentheses), and the misspecification-robust $t$-ratio of Kan et al. (2013) ( $t_{K R S}$ in square brackets). The $t$-ratio of $\hat{\gamma}_{0}$ is to examine the null hypothesis that the excess zero-beta rate is equal to zero.

Table 6

Covariance risk price estimates based on the 25 ME-Mom portfolios.

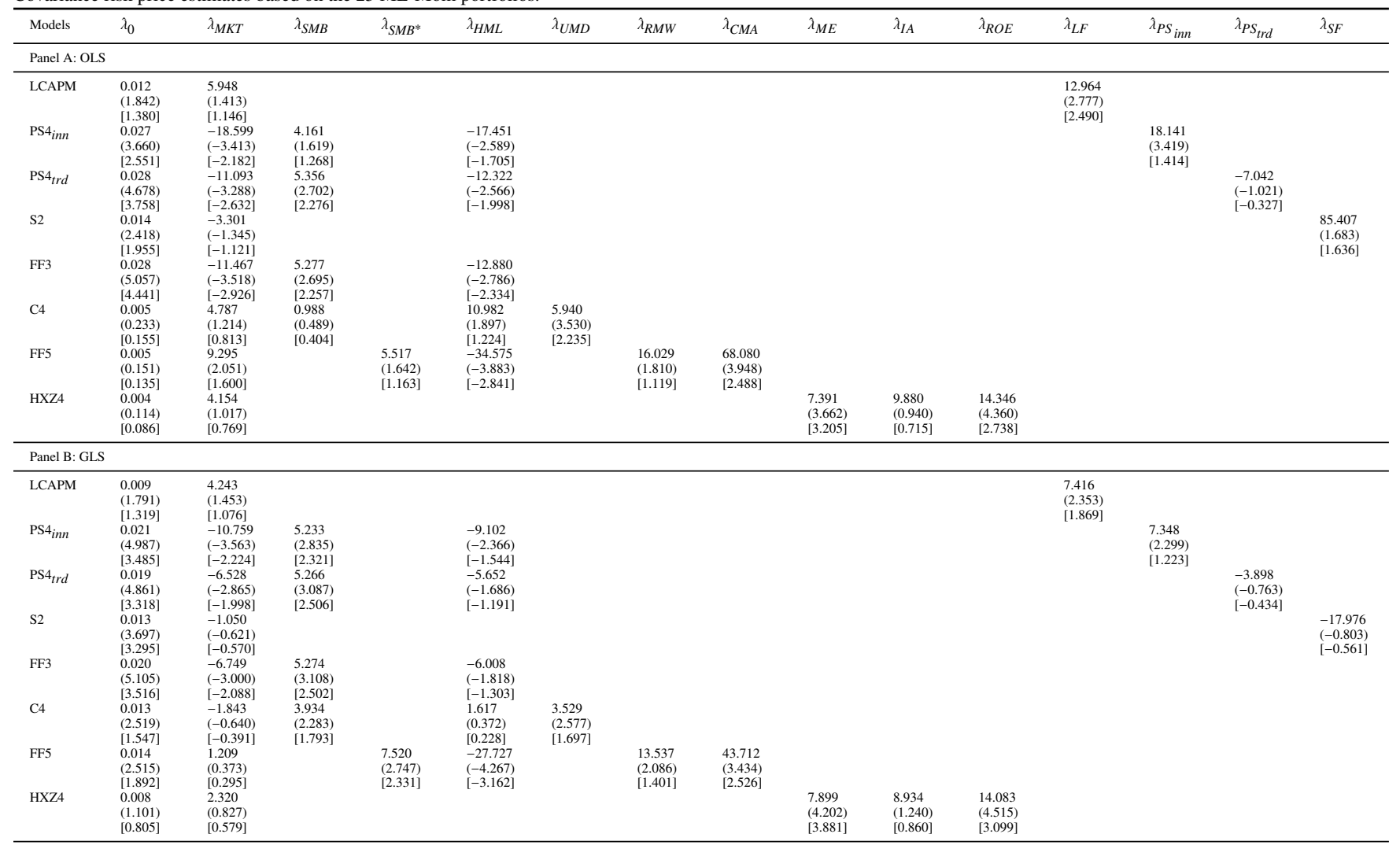

Note: This table presents the covariance risk price estimates based on the 25 ME-Mom portfolios for eight pricing models. We report parameter estimates $\hat{\lambda}$, the Shanken (1992) $t$-ratio under correctly specified models ( $t_{S}$ in parentheses), and the misspecification-robust $t$-ratio of Kan et al. (2013) ( $t_{K R S}$ in square brackets). 
Table 7

Factor-loading-related risk premiums estimated using the 32 ME-Inv-OP portfolios.

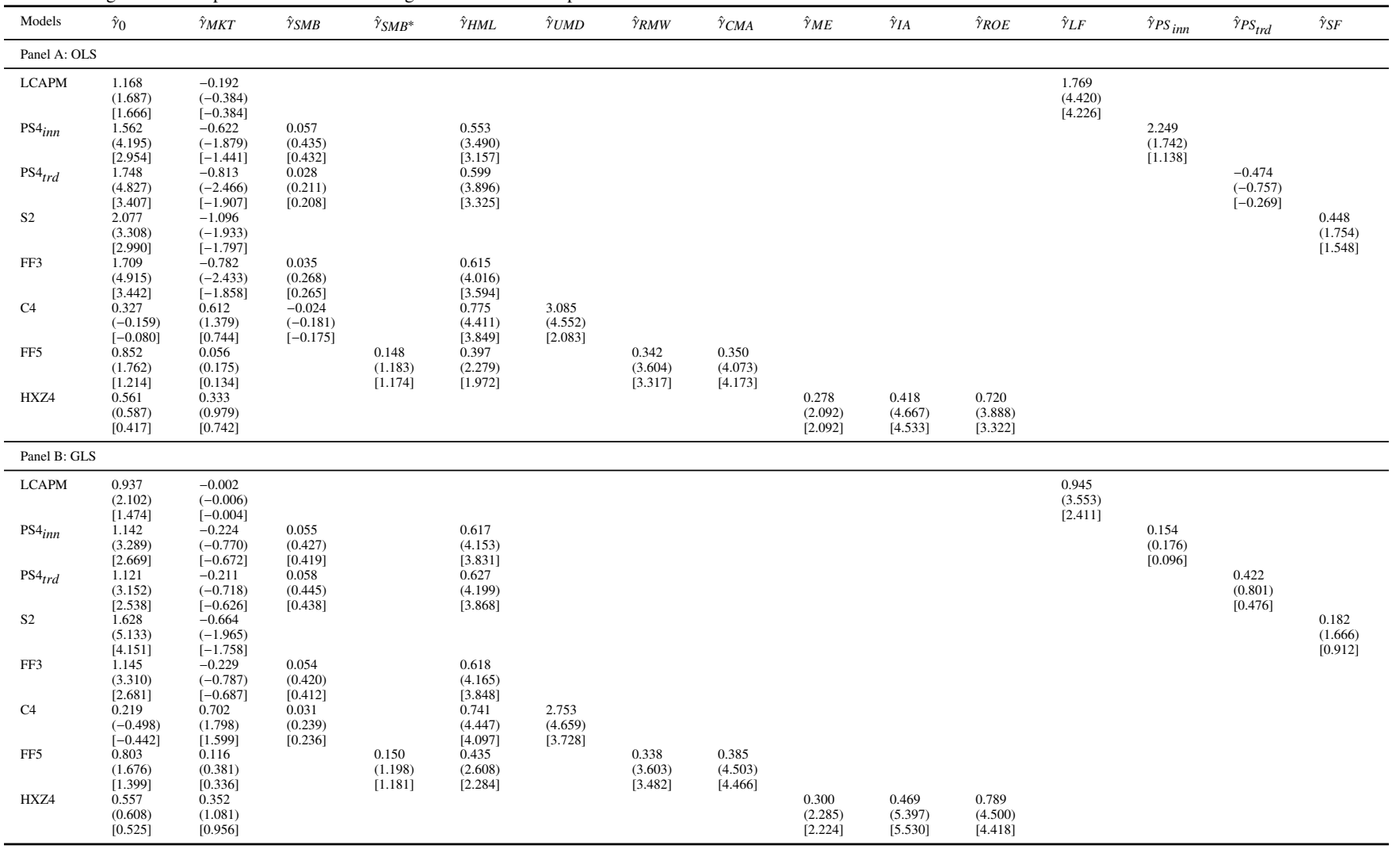

Note: This table presents the beta risk premium $(\gamma)$ estimates based on the 32 size-investment-profitability (ME-Inv-OP) portfolios for eight pricing models. Numbers in parentheses are the Shanken (1992) $t$-ratios under correctly specified models $\left(t_{S}\right)$, and numbers in square brackets are the misspecification-robust $t$-ratios of Kan et al. (2013) $\left(t_{K R S}\right)$. The $t$-ratio for $\hat{\gamma}_{0}$ tests the null hypothesis that the excess zero-beta rate is equal to zero.

Table 8

Covariance risk price estimates based on the $32 \mathrm{ME}-\mathrm{Inv}-\mathrm{OP}$ portfolios.

\begin{tabular}{|c|c|c|c|c|c|c|c|c|c|c|c|c|c|c|c|}
\hline Models & $\hat{\lambda}_{0}$ & $\hat{\lambda}_{M K T}$ & $\hat{\lambda}_{S M B}$ & $\hat{\lambda}_{S M B^{*}}$ & $\hat{\lambda}_{H M L}$ & $\hat{\lambda}_{U M D}$ & $\hat{\lambda}_{R M W}$ & $\hat{\lambda}_{C M A}$ & $\hat{\lambda}_{M E}$ & $\hat{\lambda}_{I A}$ & $\hat{\lambda}_{R O E}$ & $\hat{\lambda}_{L F}$ & $\hat{\lambda}_{P S_{i n n}}$ & $\hat{\lambda}_{P S_{t r d}}$ & $\hat{\lambda}_{S F}$ \\
\hline \multicolumn{16}{|c|}{ Panel A: OLS } \\
\hline LCAPM & $\begin{array}{l}0.012 \\
(1.687) \\
{[1.666]}\end{array}$ & $\begin{array}{l}12.023 \\
(1.934) \\
{[1.875]}\end{array}$ & & & & & & & & & & $\begin{array}{l}25.556 \\
(3.072) \\
{[3.035]}\end{array}$ & & & \\
\hline $\mathrm{PS}_{i n n}$ & $\begin{array}{l}0.016 \\
(4.195)\end{array}$ & $\begin{array}{l}-6.036 \\
(-2.194)\end{array}$ & $\begin{array}{l}2.218 \\
(1.271)\end{array}$ & & $\begin{array}{l}6.121 \\
(2.569)\end{array}$ & & & & & & & & $\begin{array}{l}8.909 \\
(1.923)\end{array}$ & & \\
\hline & {$[2.954]$} & {$[-1.739]$} & {$[1.021]$} & & {$[2.165]$} & & & & & & & & {$[1.256]$} & & \\
\hline $\mathrm{PS} 4_{t r d}$ & $\begin{array}{l}0.017 \\
(4.827)\end{array}$ & $\begin{array}{l}-3.490 \\
(-1.785)\end{array}$ & $\begin{array}{l}2.954 \\
(1.846)\end{array}$ & & $\begin{array}{l}6.569 \\
(2.984)\end{array}$ & & & & & & & & & $\begin{array}{l}-4.489 \\
(-0.812)\end{array}$ & \\
\hline S2 & $\begin{array}{l}{[3.407]} \\
0.021 \\
(3.308) \\
{[2.990]}\end{array}$ & $\begin{array}{l}{[-1.330]} \\
-7.717 \\
(-2.858) \\
{[-2.826]}\end{array}$ & {$[1.678]$} & & {$[2.533]$} & & & & & & & & & {$[-0.292]$} & $\begin{array}{l}119.455 \\
(1.857) \\
{[1.658]}\end{array}$ \\
\hline FF3 & $\begin{array}{l}0.017 \\
(4.915)\end{array}$ & $\begin{array}{l}-3.282 \\
(-1.730)\end{array}$ & $\begin{array}{l}2.959 \\
(1.868)\end{array}$ & & $\begin{array}{l}6.617 \\
(3.034)\end{array}$ & & & & & & & & & & \\
\hline $\mathrm{C} 4$ & $\begin{array}{l}{[3.442]} \\
0.003 \\
(-0.159)\end{array}$ & $\begin{array}{l}{[-1.254]} \\
9.025 \\
(2.756)\end{array}$ & $\begin{array}{l}{[1.689]} \\
0.164 \\
(0.079)\end{array}$ & & $\begin{array}{l}{[2.544]} \\
18.720 \\
(5.022)\end{array}$ & $\begin{array}{l}20.295 \\
(4.624)\end{array}$ & & & & & & & & & \\
\hline FF5 & $\begin{array}{l}{[-0.009} \\
0.009 \\
(1.762) \\
{[1.214]}\end{array}$ & $\begin{array}{l}{[1.387]} \\
2.870 \\
(1.408)\end{array}$ & {$[0.058]$} & $\begin{array}{l}3.852 \\
(2.374)\end{array}$ & $\begin{array}{l}{[2.858]} \\
-0.215 \\
(-0.055)\end{array}$ & [1.995] & $\begin{array}{l}10.342 \\
(4.213)\end{array}$ & $\begin{array}{l}11.969 \\
(2.359)\end{array}$ & & & & & & & \\
\hline HXZ4 & $\begin{array}{l}0.006 \\
(0.587) \\
{[0.417]}\end{array}$ & $\begin{array}{l}4.907 \\
(2.152) \\
{[1.547]}\end{array}$ & & {$[2.1099]$} & {$[-0.04 /]$} & & {$[3.343]$} & {$[2.290]$} & $\begin{array}{l}6.338 \\
(3.372) \\
{[3.175]}\end{array}$ & $\begin{array}{l}16.965 \\
(4.449) \\
{[3.377]}\end{array}$ & $\begin{array}{l}14.827 \\
(4.067) \\
{[3.247]}\end{array}$ & & & & \\
\hline \multicolumn{16}{|c|}{ Panel B: GLS } \\
\hline $\mathrm{PS}_{i n n}$ & $\begin{array}{l}0.011 \\
(3.289) \\
{[2.669]}\end{array}$ & $\begin{array}{l}-0.477 \\
(-0.232) \\
{[-0.1621}\end{array}$ & $\begin{array}{l}2.018 \\
(1.305) \\
\end{array}$ & & $\begin{array}{l}7.791 \\
(3.700) \\
\end{array}$ & & & & & & & & $\begin{array}{l}0.845 \\
(0.273) \\
{[0.148]}\end{array}$ & & \\
\hline $\mathrm{PS}_{t r d}$ & $\begin{array}{l}{[2.0011]} \\
(3.152) \\
{[2.538]}\end{array}$ & $\begin{array}{l}-0.042] \\
-0.0242 \\
(-0.02020] \\
{[-0.02}\end{array}$ & $\begin{array}{l}2.055 \\
(1.333) \\
{[1.229]}\end{array}$ & & $\begin{array}{l}7.3 .351 \\
7.771 \\
(3.668) \\
{[3.294]}\end{array}$ & & & & & & & & & $\begin{array}{l}3.401 \\
(0.732) \\
{[0.436]}\end{array}$ & \\
\hline S2 & $\begin{array}{l}{[2.536]} \\
0.01633 \\
{[5.131]} \\
{[4.151]}\end{array}$ & $\begin{array}{l}-0.0225] \\
(-2.220) \\
{[-2.144]}\end{array}$ & & & & & & & & & & & & & $\begin{array}{l}49.662 \\
(1.783) \\
{[0.992]}\end{array}$ \\
\hline FF3 & $\begin{array}{l}0.011 \\
(3.310) \\
{[2.681]}\end{array}$ & $\begin{array}{l}-0.168 \\
(-0.098) \\
{[-0.081]}\end{array}$ & $\begin{array}{l}2.074 \\
(1.354) \\
{[1.248]}\end{array}$ & & $\begin{array}{l}7.801 \\
(3.708) \\
{[3.356]}\end{array}$ & & & & & & & & & & \\
\hline $\mathrm{C} 4$ & $\begin{array}{l}0.002 \\
(-0.498) \\
{[-0.442]}\end{array}$ & $\begin{array}{l}8.990 \\
(3.099) \\
{[2.599]}\end{array}$ & $\begin{array}{l}0.531 \\
(0.269) \\
{[0.246]}\end{array}$ & & $\begin{array}{l}17.860 \\
(5.202) \\
{[3.946]}\end{array}$ & $\begin{array}{l}18.397 \\
(4.790) \\
{[3.170]}\end{array}$ & & & & & & & & & \\
\hline FF5 & $\begin{array}{l}-0.008 \\
0.008 \\
(1.676)\end{array}$ & $\begin{array}{l}3.445 \\
(1.762)\end{array}$ & & $\begin{array}{l}3.748 \\
(2.316)\end{array}$ & $\begin{array}{l}-0.165 \\
(-0.044)\end{array}$ & & $\begin{array}{l}10.486 \\
(4.361)\end{array}$ & $\begin{array}{l}13.269 \\
(2.710)\end{array}$ & & & & & & & \\
\hline & [1.399] & {$[1.523]$} & & {$[2.120]$} & {$[-0.037]$} & & [3.900] & [2.496] & & & & & & & \\
\hline HXZ4 & $\begin{array}{l}0.006 \\
(0.608) \\
{[0.525]}\end{array}$ & $\begin{array}{l}5.363 \\
(2.458) \\
{[2.167]}\end{array}$ & & & & & & & $\begin{array}{l}6.926 \\
(3.684) \\
{[3.293]}\end{array}$ & $\begin{array}{l}18.884 \\
(5.098) \\
{[4.519]}\end{array}$ & $\begin{array}{l}16.221 \\
(4.677) \\
{[4.322]}\end{array}$ & & & & \\
\hline
\end{tabular}

Note: This table presents the covariance risk price $(\lambda)$ estimates based on the 32 size-investment-profitability (ME-Inv-OP) portfolios for eight pricing models. Numbers in parentheses are the Shanken (1992) $t$-ratios under correctly specified models $\left(t_{S}\right)$, and numbers in square brackets are the misspecification-robust $t$-ratios of Kan et al. (2013) $\left(t_{K R S}\right)$. 
captures multidimensions of liquidity and yields a robust premium, shows significant liquidity risk/beta premium regardless of which test statistic, which estimation method, and which set of testing portfolios we use. Covariances of asset returns with the liquidity risk factor of the LCAPM (18) also show the improvement of the factor to explain stock returns based on any set of testing portfolios and estimation methods except for the GLS estimate against the $25 \mathrm{ME}-\mathrm{ME} / \mathrm{BE}$ portfolios. Nevertheless, the covariance risk premiums of all other factors (except for the size factor) are also insignificant based on the GLS estimates with the 25 ME-ME/BE portfolios (see Table 4). We also find consistent evidence with Fama and French (2015) that the firm characteristics-based factors such as momentum, investment, and profitability factors show good performance against the test portfolios formed on these characteristics. Given the two-factor LCAPM (18) that includes no firm-characteristics-based factors, which some of them are present in the three-, four-, and five-factor models examined, the significant liquidity risk premium estimate from the LCAPM against these three sets of testing portfolios provides supportive evidence that liquidity risk is priced and important for asset pricing.

\section{Model performance}

In this section, we assess the performance of liquidity-risk-based models in comparison with non-liquidity-risk-based pricing models based on the squared Sharpe ratio metric, $S h^{2}(f)$. First, we construct comparison tests according to the methods proposed by Barillas and Shanken (2017) and Barillas et al. (2019). Second, we use the Monte Carlo simulation method to check the robustness of the results. Third, we analyze each factor's marginal contribution in improving models' $S h^{2}(f) 10$

\subsection{Model comparison tests based on the squared Sharpe ratio metric, $\operatorname{Sh}^{2}(f)$}

Table 9 presents the results of pairwise comparison test (Panel A) and multiple model comparison test (Panel B) based on $S h^{2}(f){ }^{11}$ We observe the top two $S h^{2}(f)$ values from the HXZ4 and the LCAPM at 0.169 and 0.133 (see Panel B). The difference between the top two $S h^{2}(f)$ values reported in Panel A is insignificant at 0.037 ( $p$-value $=0.361$ ), indicating that the HXZ4 and the LCAPM are comparable. The $S h^{2}(f)$ differences in Panel A also show that the LCAPM is comparable with the FF5 (the former has a larger $S h^{2}(f)$ than the latter, but the difference is insignificant). In addition, the $S h^{2}(f)$ value from the LCAPM is significantly higher at the $10 \%$ level than the ones obtained from the FF3, C4, and the PS4 $4_{t r d}$. The multiple model comparison tests with the likelihood ratio $(L R)$ statistics in Panel B provide a consistent picture of the performance of

\footnotetext{
${ }^{10}$ The methods of Barillas et al. (2019) are suitable for comparing models with traded factor(s). Thus, we exclude the non-traded factors of Pástor and Stambaugh (2003) and Sadka (2006).

${ }^{11}$ Panel A of table 9 presents the bias-adjusted difference in the maximum squared Sharpe ratios between every pair of competitive models. The corresponding $p$-value (in parentheses) has different interpretations depending on whether a model is nested relative to its counterpart. Specifically, for the comparison of nested models, the corresponding $p$-value is used to determine if the regression intercept of the extra factor on the nested model is zero; whereas for non-nested models, we report the normal test $p$-value based on the proposition of Barillas et al. (2019). We also perform the sequence test of Barillas et al. (2019) and obtain qualitatively similar results, which are untabulated.
} 
competing models. Of all the models investigated, we only fail to reject the null hypotheses that the LCAPM performs as good as the HXZ4 and as good as the FF5. Other tests show better performance of the LCAPM relative to the FF3, the C4, and the $\mathrm{PS}_{\text {trd }}$.

Table 9

Model comparison tests based on the squared Sharpe ratio metric, $S^{2}(f)$

\begin{tabular}{|c|c|c|c|c|c|c|c|c|c|c|}
\hline \multirow[t]{2}{*}{ Model } & \multicolumn{2}{|c|}{$\mathrm{PS} 4_{\text {trd }}$} & \multicolumn{2}{|c|}{$\mathrm{C} 4$} & \multicolumn{2}{|c|}{ FF5 } & \multicolumn{2}{|c|}{ LCAPM } & \multicolumn{2}{|c|}{ HXZ4 } \\
\hline & diff & $p$-value & diff & $p$-value & diff & $p$-value & diff & $p$-value & diff & $p$-value \\
\hline FF3 & 0.009 & $(0.015)$ & 0.041 & $(0.000)$ & 0.061 & $(0.004)$ & 0.097 & $(0.001)$ & 0.134 & $(0.000)$ \\
\hline $\mathrm{PS} 4_{t r d}$ & & & 0.032 & $(0.141)$ & 0.052 & $(0.027)$ & 0.089 & $(0.004)$ & 0.125 & $(0.001)$ \\
\hline $\mathrm{C} 4$ & & & & & 0.020 & $(0.446)$ & 0.056 & $(0.073)$ & 0.093 & $(0.001)$ \\
\hline FF5 & & & & & & & 0.037 & $(0.258)$ & 0.073 & $(0.004)$ \\
\hline LCAPM & & & & & & & & & 0.037 & $(0.361)$ \\
\hline \multicolumn{11}{|c|}{ Panel B: Multiple model comparison } \\
\hline Model & $S h^{2}(f)$ & $n$ & $L R$ & & $p$-value & & & & & \\
\hline FF3 & 0.035 & 3 & 21.698 & & 0.000 & & & & & \\
\hline $\mathrm{PS} 4_{t r d}$ & 0.044 & 4 & 16.021 & & 0.000 & & & & & \\
\hline $\mathrm{C} 4$ & 0.076 & 4 & 12.349 & & 0.002 & & & & & \\
\hline HXZ4 & 0.169 & 4 & 0.000 & & 0.740 & & & & & \\
\hline
\end{tabular}

Note: Panel A reports the difference (diff) between the $S h^{2}(f)$ values of the models in column $i$ and row $j$. The $p$-value (in parentheses) is to test the null that the two competing models have the same $S h^{2}(f)$. Panel B reports the results of multiple model comparison tests. In Panel B, the column labeled $n$ shows the number of competing models in each non-nested model comparison, and the last column shows that $p$-values corresponding to the likelihood ratio $(L R)$ statistics.

\subsection{Monte Carlo simulation results}

In order to avoid the influence of the sample selection on our results, in this subsection we undertake a Monte Carlo simulation test procedure for robustness. In our simulation designs, the factor values are drawn from a normal distribution, where the mean and variance of the simulated factors are set to the sample mean and variance estimated from the data. The number of time series observations is set to 600 , which is equal to the actual sample size of 600 monthly observations, and all results are based on 100,000 Monte Carlo replications. Table 10 reports the simulation results. Panel A shows that the mean and median of the $S h^{2}(f)$ difference are similar to the actual sample $S h^{2}(f)$ difference for each pairwise comparison. Consistent with the evidence in Table 9, the two largest $S h^{2}(f)$ values are again observed from the HXZ4 and the LCAPM (see Table 10, Panel B). The LCAPM outperforms the FF5 and the C4 in $77.9 \%$ and $94.6 \%$ of simulation runs, and outperforms the PS4 ${ }_{\text {trd }}$ and the FF3 in $99.8 \%$ and $100 \%$ of simulation runs. For the multiple model comparison tests, the Monte Carlo simulation results in Panel B of Table 10 show that the HXZ4 and the LCAPM take the first place among the competing models in $99.97 \%$ and $88.29 \%$ of the simulation runs. In contrast, the remaining models rank first in no more than $24.76 \%$ of simulation runs. Overall, the Monte Carlo simulation results show consistent evidence that the HXZ4 and the LCAPM perform better than other pricing models based on the $S h^{2}(f)$ metric. 
Monte Carlo simulation results.

\begin{tabular}{|c|c|c|c|c|c|c|c|c|c|c|c|c|c|c|c|}
\hline \multicolumn{16}{|c|}{ Panel A: Pairwise model comparison } \\
\hline \multirow[t]{2}{*}{ Model } & \multicolumn{3}{|c|}{$\mathrm{PS} 4_{\text {trd }}$} & \multicolumn{3}{|c|}{$\mathrm{C} 4$} & \multicolumn{3}{|c|}{ FF5 } & \multicolumn{3}{|c|}{ LCAPM } & \multicolumn{3}{|c|}{ HXZ4 } \\
\hline & Average & Median & $\%>0$ & Average & Median & $\%>0$ & Average & Median & $\%>0$ & Average & Median & $\%>0$ & Average & Median & $\%>0$ \\
\hline FF3 & 0.012 & 0.011 & 100.0 & 0.045 & 0.043 & 100.0 & 0.069 & 0.067 & 100.0 & 0.095 & 0.094 & 100.0 & 0.140 & 0.138 & 100.0 \\
\hline $\mathrm{PS} 4_{\text {trd }}$ & & & & 0.033 & 0.032 & 96.0 & 0.057 & 0.055 & 99.5 & 0.083 & 0.081 & 99.8 & 0.127 & 0.125 & 100.0 \\
\hline $\mathrm{C} 4$ & & & & & & & 0.024 & 0.023 & 82.1 & 0.049 & 0.049 & 94.6 & 0.094 & 0.093 & 100.0 \\
\hline LCAPM & & & & & & & & & & & & & 0.045 & 0.044 & 86.6 \\
\hline \multicolumn{16}{|c|}{ Panel B: Multiple model comparison } \\
\hline Model & & $S h^{2}(f)$ & & $\%>0$ & & & & & & & & & & & \\
\hline FF3 & & 0.041 & & 0.01 & & & & & & & & & & & \\
\hline $\mathrm{PS} 4_{\text {trd }}$ & & 0.051 & & 2.95 & & & & & & & & & & & \\
\hline $\mathrm{C} 4$ & & 0.084 & & 12.37 & & & & & & & & & & & \\
\hline LCAPM & & 0.137 & & 88.29 & & & & & & & & & & & \\
\hline HXZ4 & & 0.178 & & 99.97 & & & & & & & & & & & \\
\hline
\end{tabular}

Note: Panel A reports the average and median of the $S h^{2}(f)$ differences between the models in column $i$ and row $j$ from 100,000 simulations. Panel A also shows the percentage of the simulation runs in which the difference is positive $(\%>0)$. Panel B reports the simulation results of multiple model comparison tests. The column labeled $\%>0$ in Panel B shows the percentage of the simulation runs in which the model dominates competing models.

\subsection{The marginal contribution of factors to $\operatorname{Sh}^{2}(f)$}

According to Barillas and Shanken (2017), when adding factor $i$ to model $f$, there is an increase in model $f$ 's $S h^{2}(f)$, and the increase is factor $i$ 's marginal contribution to $S h^{2}(f)$. This increment is calculated by

$$
S h^{2}(f, i)-S h^{2}(f)=a_{i}^{2} / \sigma_{i}^{2},
$$

where $a_{i}$ is the intercept in the spanning regression of factor $i$ on the factor(s) of model $f$, and $\sigma_{i}$ is the standard deviation of the regression residuals. For empirical tests, to assess factor $i$ 's marginal contribution, we find $a_{i}$ and $\sigma_{i}$ of equation (21) by running the regression of factor $i$ on the remaining factors. Because of the high correlations between the FF5 factors and the HXZ4 factors, we conduct our analysis separately based on two groups of factors: (i) the FF5 factors plus the non-HXZ4 factors; and (ii) the HXZ4 factors plus the non-FF5 factors.

Table 11, Panel A shows the results of regressing each of the eight factors (MKT, SMB* ${ }^{*}, H M L, R M W, C M A, U M D, P S_{t r d}$ and $L F$ ) on the remaining seven factors. Regressing $L F$ on other seven factors produces a significant intercept of $0.6 \%$ per month $(t=5.647)$, and the corresponding marginal contribution is 0.061 , which is the second largest contributor to $S h^{2}(f)$. The largest marginal contribution to $S h^{2}(f)$ stems from the market factor, which is expected. After all, all the models examined are the extensions to the CAPM. The PS traded factor, $P S_{t r d}$, also has a significant intercept of $0.4 \%$ per month $(t=2.428)$ with a marginal contribution to $S h^{2}(f)$ of 0.012 , which is the third lowest among the eight factors. The intercepts estimates of $R M W, C M A$, and $U M D$ are also significant, but the size factor and the book-to-market factor show insignificant intercept estimates and trivial marginal contributions to $S h^{2}(f)$. This is in accord with the fact that the size effect has disappeared since 
its documentation. The weak performance of $H M L$ is in line with Fama and French (2018) who find that $H M L$ is negligible.

Table 11

A factor's marginal contributions to the squared Sharpe ratio $S h^{2}(f)$.

\begin{tabular}{|c|c|c|c|c|c|c|c|c|c|c|c|c|c|c|}
\hline Factor & $a$ & $L F$ & $P S_{t r d}$ & $M K T$ & $S M B^{*}$ & $H M L$ & $R M W$ & $C M A$ & $U M D$ & $t(a)$ & $R^{2}$ & $s(e)$ & $S h^{2}(f)$ & $a^{2} / s^{2}(e)$ \\
\hline$L F$ & 0.006 & & 0.003 & -0.424 & 0.098 & 0.175 & 0.133 & 0.215 & 0.123 & 5.647 & 0.515 & 0.024 & 0.207 & 0.061 \\
\hline$P S_{t r d}$ & 0.004 & 0.006 & & -0.007 & -0.004 & 0.073 & -0.019 & -0.052 & -0.008 & 2.428 & -0.009 & 0.034 & 0.207 & 0.012 \\
\hline$M K T$ & 0.011 & -0.768 & -0.006 & & 0.246 & 0.138 & -0.121 & -0.418 & 0.015 & 7.836 & 0.490 & 0.032 & 0.207 & 0.112 \\
\hline$S M B^{*}$ & 0.002 & 0.132 & -0.002 & 0.183 & & 0.002 & -0.458 & -0.063 & -0.007 & 1.223 & 0.171 & 0.028 & 0.207 & 0.003 \\
\hline$H M L$ & -0.000 & 0.117 & 0.024 & 0.051 & 0.001 & & 0.131 & 0.963 & -0.141 & -0.201 & 0.544 & 0.019 & 0.207 & 0.000 \\
\hline$R M W$ & 0.003 & 0.094 & -0.007 & -0.047 & -0.240 & 0.139 & & -0.293 & 0.044 & 3.371 & 0.191 & 0.020 & 0.207 & 0.022 \\
\hline$C M A$ & 0.002 & 0.067 & -0.008 & -0.072 & -0.014 & 0.450 & -0.129 & & 0.039 & 3.041 & 0.564 & 0.013 & 0.207 & 0.018 \\
\hline$U M D$ & 0.004 & 0.348 & -0.011 & 0.023 & -0.015 & -0.598 & 0.178 & 0.357 & & 2.507 & 0.129 & 0.040 & 0.207 & 0.013 \\
\hline
\end{tabular}

Panel B: Pooled regressions consist of $M K T, M E, I A, R O E, U M D, L F$ and $P S_{t r d}$

\begin{tabular}{|c|c|c|c|c|c|c|c|c|c|c|c|c|c|}
\hline Factor & $a$ & $L F$ & $P S_{t r d}$ & $M K T$ & $M E$ & $I A$ & $R O E$ & $U M D$ & $t(a)$ & $R^{2}$ & $s(e)$ & $S h^{2}(f)$ & $a^{2} / s^{2}(e)$ \\
\hline$L F$ & 0.006 & & 0.006 & -0.445 & 0.076 & 0.389 & 0.005 & 0.098 & 5.703 & 0.494 & 0.024 & 0.262 & 0.065 \\
\hline$P S_{t r d}$ & 0.004 & 0.012 & & -0.006 & -0.054 & 0.030 & -0.175 & 0.032 & 2.850 & 0.003 & 0.034 & 0.262 & 0.017 \\
\hline$M K T$ & 0.011 & -0.785 & -0.005 & & 0.235 & -0.244 & -0.097 & 0.020 & 7.749 & 0.482 & 0.032 & 0.262 & 0.115 \\
\hline$M E$ & 0.003 & 0.099 & -0.037 & 0.175 & & -0.108 & -0.456 & 0.128 & 2.589 & 0.171 & 0.028 & 0.262 & 0.014 \\
\hline$I A$ & 0.004 & 0.183 & 0.007 & -0.065 & -0.039 & & -0.031 & -0.021 & 4.824 & 0.201 & 0.017 & 0.262 & 0.047 \\
\hline$R O E$ & 0.005 & 0.004 & -0.065 & -0.039 & -0.245 & -0.046 & & 0.286 & 5.259 & 0.352 & 0.020 & 0.262 & 0.056 \\
\hline
\end{tabular}

Note: Panel A reports the results of the eight factors: the FF5 factors plus the non-HXZ4 factors. Panel B reports the results of the seven factors: the HXZ4 factors plus the non-FF5 factors. For each Panel, we regress each factor on the remaining factors included in the panel. We report the regression intercept estimates $(a), t$-ratios of the intercept estimates $(t(a))$, slope coefficients, $R^{2}$, standard errors of regression residuals $(s(e))$, the maximum squared Sharpe ratio $\left(S h^{2}(f)\right)$, and the marginal contribution of each factor to $S h^{2}(f)\left(a^{2} / s^{2}(e)\right)$

Table 11, Panel B reports the results of the seven factors, i.e., the HXZ4 factors plus the non-FF5 factors $(M K T, M E, I A$, $R O E, U M D, P S_{t r d}$ and $L F$ ). Similar to the results of Panel A, $L F$, the liquidity risk factor of the LCAPM (18), once again has a significant intercept estimate of $0.6 \%(t=5.703)$ per month and produces the largest marginal contribution of 0.065 to $S h^{2}(f)$ among all non-market factors. The size factor ME of HXZ4 also has the second lowest marginal contribution to $S h^{2}(f)$, mirroring the size factor of the FF5 in Panel A. Compared with Panel A, a major difference is that the momentum factor $U M D$ has an insignificant intercept estimate and makes little marginal contribution to $S h^{2}(f)$, which appears consistent with the argument of Hou et al. (2017) that the profitability factor helps to explain the momentum premium.

Overall, the results related to the squared Sharpe ratio $\left(S h^{2}(f)\right)$ in this section show that the LCAPM 18) performs no worse but generally better than other models examined. The liquidity risk factor $L F$ of the LCAPM yields the largest marginal contribution in improving models' $S h^{2}(f)$ among all competing factors. The evidence provides support for the significant liquidity risk premium found in the previous section and for the importance of liquidity risk in asset pricing.

\section{Market conditions and subperiods}

Previous studies show that changes in market liquidity are closely related to economic conditions (Pástor and Stambaugh 2003; Liu, 2006; Kamara et al., 2008; Hameed et al., 2010; Næs et al., 2011; Switzer and Picard, 2016). Thus, we perform 
further tests by considering different economic conditions and subperiods. We only focus on the liquidity risk-based models to save space. To further ascertain the uniqueness of liquidity risk, we also extend the FF5 respectively by each of the liquidity factors examined in this study. We conduct the tests using the $25 \mathrm{ME}-\mathrm{BE} / \mathrm{ME}$ portfolios and report the OLS estimates of the factor loading premiums $(\gamma)$.

\subsection{Market conditions and pricing factors/models}

We use stock market excess return $\left(R_{m}-R_{f}\right)$ and stock market volatility $\left(\operatorname{Var}_{m}\right)$ to proxy for market conditions 12 Table 12 shows that liquidity risk estimated with the LCAPM (18) is significantly priced during the down market (Panel A). The LCAPMbased liquidity risk premium is also significant at the $10 \%$ and $5 \%$ levels in both the low- and high-volatility markets (Panel B). Highly priced liquidity risk during the down market and the market turmoil is consistent with the economic intuition, i.e., investors require a high premium in bad times. Other liquidity factors/models, on the other hand, generally show insignificant liquidity risk premium regardless of whether we classify the market conditions based on the stock market performance or on the stock market volatility. For the subperiod results, Table 12, Panel C shows that the estimated liquidity risk premiums associated with the PS traded factor $P S_{t r d}$ and the trading-discontinuity-based factor of the LCAPM are significant in the first half of the sample period. However, the estimated risk premiums related to all risk factors including the FF5 factors tend to be insignificant in the second half of the sample period. Furthermore, we examine the pricing performance of liquidity factors after controlling for the FF5 factors (after controlling for the HXZ4 factors, we obtain the similar results, which are not tabulated). Consistently, the liquidity risk premiums associated with the liquidity risk factor of the LCAPM $[18$ remain statistically significant after controlling for the FF5 factors during the down and high-volatility markets. In fact, the risk premium estimates associated with the FF5 factors are all insignificant during the high-volatility market, indicating that the liquidity risk factor of the LCAPM (18) captures different information from the FF5 factors. For the two PS liquidity factors and the Sadka factor, they again do not yield significant liquidity risk premiums after controlling for the FF5 factors, further indicating that the trading-discontinuity-based liquidity factor of the LCAPM (18) differs from the PS and the Sadka factors. Moreover, we examine the impact of the January effect on our results by excluding January returns. Untabulated results show that removing January returns from our sample does not alter our inferences.

Table 12

Factor loading premium estimated with the $25 \mathrm{ME}-\mathrm{BE} / \mathrm{ME}$ portfolios.

\begin{tabular}{|c|c|c|c|c|c|c|c|c|c|c|c|}
\hline Models & $\hat{\gamma}_{0}$ & $\hat{\gamma}_{M K T}$ & $\hat{\gamma}_{S M B}$ & $\hat{\gamma}_{S M B^{*}}$ & $\hat{\gamma}_{H M L}$ & $\hat{\gamma}_{R M W}$ & $\hat{\gamma}_{C M A}$ & $\hat{\gamma}_{L F}$ & $\hat{\gamma}_{P S_{i n n}}$ & $\hat{\gamma}_{P S_{t r d}}$ & $\hat{\gamma}_{S F}$ \\
\hline
\end{tabular}

\footnotetext{
${ }^{12}$ The excess market return $\left(R_{m}-R_{f}\right)$ is the return of the CRSP value-weighed NYSE/AMEX/ARCA/NASDAQ stock market index in excess of the onemonth T-bill rate. We use $R_{m}-R_{f}$ to distinguish the up-market (i.e., $R_{m}-R_{f}>0$ ) from the down-market (i.e., $R_{m}-R_{f}<0$ ). Market volatility (Var $r_{m}$ ) is the realized return variance of the stock market obtained from Amit Goyal's website. We divide the market into high- and low-volatility periods according to the median of the $\operatorname{Var}_{m}$ series.
} 
Table 12 (continued)

\begin{tabular}{|c|c|c|c|c|c|c|c|c|c|c|c|}
\hline Models & $\hat{\gamma}_{0}$ & $\hat{\gamma}_{M K T}$ & $\hat{\gamma}_{S M B}$ & $\hat{\gamma}_{S M B^{*}}$ & $\hat{\gamma}_{H M L}$ & $\hat{\gamma}_{R M W}$ & $\hat{\gamma}_{C M A}$ & $\hat{\gamma}_{L F}$ & $\hat{\gamma}_{P S_{i n n}}$ & $\hat{\gamma}_{P S_{\text {trd }}}$ & $\hat{\gamma}_{S F}$ \\
\hline \multicolumn{12}{|c|}{ Up market, i.e. $R_{m}-R_{f}>0$} \\
\hline LCAPM & $\begin{array}{l}-0.021 \\
{[-0.183]}\end{array}$ & $\begin{array}{l}4.073 \\
{[1.973]}\end{array}$ & & & & & & $\begin{array}{l}-0.988 \\
{[-1.594]}\end{array}$ & & & \\
\hline $\mathrm{PS} 4_{i n n}$ & $\begin{array}{l}1.313 \\
{[1.734]}\end{array}$ & $\begin{array}{l}2.454 \\
{[4.649]}\end{array}$ & $\begin{array}{l}0.711 \\
{[4.271]}\end{array}$ & & $\begin{array}{l}-0.166 \\
{[-1.116]}\end{array}$ & & & & $\begin{array}{l}-0.985 \\
{[-0.514]}\end{array}$ & & \\
\hline $\mathrm{PS} 4_{t r d}$ & $\begin{array}{l}1.242 \\
{[1.683]}\end{array}$ & $\begin{array}{l}2.506 \\
{[4.928]}\end{array}$ & $\begin{array}{l}0.716 \\
{[4.345]}\end{array}$ & & $\begin{array}{l}-0.177 \\
{[-1.182]}\end{array}$ & & & & & $\begin{array}{l}-0.143 \\
{[-0.086]}\end{array}$ & \\
\hline S2 & $\begin{array}{l}1.948 \\
{[0.915]}\end{array}$ & $\begin{array}{l}2.107 \\
{[1.319]}\end{array}$ & & & & & & & & & $\begin{array}{l}0.663 \\
{[0.681]}\end{array}$ \\
\hline $\mathrm{FF} 5+L F$ & $\begin{array}{l}2.315 \\
{[2.447]}\end{array}$ & $\begin{array}{l}1.391 \\
{[1.780]}\end{array}$ & & $\begin{array}{l}0.793 \\
{[4.801]}\end{array}$ & $\begin{array}{l}-0.178 \\
{[-1.177]}\end{array}$ & $\begin{array}{l}-0.192 \\
{[-0.714]}\end{array}$ & $\begin{array}{l}-0.484 \\
{[-1.139]}\end{array}$ & $\begin{array}{l}-1.525 \\
{[-5.445]}\end{array}$ & & & \\
\hline $\mathrm{FF} 5+P S_{i n n}$ & $\begin{array}{l}1.331 \\
{[1.444]}\end{array}$ & $\begin{array}{l}2.408 \\
{[3.693]}\end{array}$ & & $\begin{array}{l}0.745 \\
{[4.400]}\end{array}$ & $\begin{array}{l}-0.199 \\
{[-1.305]}\end{array}$ & $\begin{array}{l}-0.123 \\
{[-0.350]}\end{array}$ & $\begin{array}{l}-0.385 \\
{[-0.545]}\end{array}$ & & $\begin{array}{l}-1.558 \\
{[-0.699]}\end{array}$ & & \\
\hline $\mathrm{FF} 5+P S_{t r d}$ & $\begin{array}{l}1.408 \\
{[1.492]}\end{array}$ & $\begin{array}{l}2.303 \\
{[3.389]}\end{array}$ & & $\begin{array}{l}0.763 \\
{[4.589]}\end{array}$ & $\begin{array}{l}-0.199 \\
{[-1.323]}\end{array}$ & $\begin{array}{l}-0.041 \\
{[-0.126]}\end{array}$ & $\begin{array}{l}-0.630 \\
{[-0.878]}\end{array}$ & & & $\begin{array}{l}0.080 \\
{[0.039]}\end{array}$ & \\
\hline $\mathrm{FF} 5+S F$ & $\begin{array}{l}1.852 \\
{[1.634]}\end{array}$ & $\begin{array}{l}1.899 \\
{[2.118]}\end{array}$ & & $\begin{array}{l}0.577 \\
{[2.628]}\end{array}$ & $\begin{array}{l}-0.245 \\
{[-1.216]}\end{array}$ & $\begin{array}{l}0.102 \\
{[0.198]}\end{array}$ & $\begin{array}{l}-0.916 \\
{[-0.775]}\end{array}$ & & & & $\begin{array}{l}0.420 \\
{[1.230]}\end{array}$ \\
\hline \multicolumn{12}{|c|}{ Down market, i.e. $R_{m}-R_{f}<0$} \\
\hline LCAPM & $\begin{array}{l}0.714 \\
{[0.420]}\end{array}$ & $\begin{array}{l}-4.011 \\
{[-5.283]}\end{array}$ & & & & & & $\begin{array}{l}2.728 \\
{[5.939]}\end{array}$ & & & \\
\hline $\mathrm{PS} 4_{i n n}$ & $\begin{array}{l}1.142 \\
{[1.078]}\end{array}$ & $\begin{array}{l}-4.628 \\
{[-6.295]}\end{array}$ & $\begin{array}{l}-0.760 \\
{[-3.837]}\end{array}$ & & $\begin{array}{l}1.151 \\
{[5.755]}\end{array}$ & & & & $\begin{array}{l}-2.008 \\
{[-0.852]}\end{array}$ & & \\
\hline $\mathrm{PS} 4_{t r d}$ & $\begin{array}{l}1.470 \\
{[1.431]}\end{array}$ & $\begin{array}{l}-4.946 \\
{[-6.243]}\end{array}$ & $\begin{array}{l}-0.786 \\
{[-3.931]}\end{array}$ & & $\begin{array}{l}1.185 \\
{[5.569]}\end{array}$ & & & & & $\begin{array}{l}-1.143 \\
{[-0.579]}\end{array}$ & \\
\hline S2 & $\begin{array}{l}1.738 \\
{[1.123]}\end{array}$ & $\begin{array}{l}-4.880 \\
{[-3.729]}\end{array}$ & & & & & & & & & $\begin{array}{l}-0.235 \\
{[-0.298]}\end{array}$ \\
\hline $\mathrm{FF} 5+L F$ & $\begin{array}{l}-0.621 \\
{[-1.497]}\end{array}$ & $\begin{array}{l}-2.771 \\
{[-3.884]}\end{array}$ & & $\begin{array}{l}-0.568 \\
{[-2.681]}\end{array}$ & $\begin{array}{l}1.185 \\
{[5.643]}\end{array}$ & $\begin{array}{l}1.531 \\
{[3.032]}\end{array}$ & $\begin{array}{l}0.480 \\
{[1.250]}\end{array}$ & $\begin{array}{l}2.437 \\
{[6.662]}\end{array}$ & & & \\
\hline $\mathrm{FF} 5+P S_{i n n}$ & $\begin{array}{l}0.562 \\
{[0.217]}\end{array}$ & $\begin{array}{l}-4.092 \\
{[-5.084]}\end{array}$ & & $\begin{array}{l}-0.549 \\
{[-2.411]}\end{array}$ & $\begin{array}{l}1.139 \\
{[5.574]}\end{array}$ & $\begin{array}{l}0.880 \\
{[1.561]}\end{array}$ & $\begin{array}{l}1.162 \\
{[2.827]}\end{array}$ & & $\begin{array}{l}-3.195 \\
{[-1.018]}\end{array}$ & & \\
\hline $\mathrm{FF} 5+P S_{t r d}$ & $\begin{array}{l}0.738 \\
{[0.456]}\end{array}$ & $\begin{array}{l}-4.216 \\
{[-5.381]}\end{array}$ & & $\begin{array}{l}-0.529 \\
{[-2.505]}\end{array}$ & $\begin{array}{l}1.139 \\
{[5.272]}\end{array}$ & $\begin{array}{l}1.055 \\
{[2.089]}\end{array}$ & $\begin{array}{l}1.255 \\
{[2.870]}\end{array}$ & & & $\begin{array}{l}-2.144 \\
{[-1.281]}\end{array}$ & \\
\hline $\mathrm{FF} 5+S F$ & $\begin{array}{l}-0.368 \\
{[-0.725]}\end{array}$ & $\begin{array}{l}-3.250 \\
{[-2.760]}\end{array}$ & & $\begin{array}{l}-0.369 \\
{[-1.434]}\end{array}$ & $\begin{array}{l}1.016 \\
{[3.523]}\end{array}$ & $\begin{array}{l}1.696 \\
{[3.612]}\end{array}$ & $\begin{array}{l}1.431 \\
{[3.115]}\end{array}$ & & & & $\begin{array}{l}-0.788 \\
{[-1.715]}\end{array}$ \\
\hline \multicolumn{12}{|c|}{ Panel B: Low- and high-volatility markets } \\
\hline \multicolumn{12}{|c|}{ Low-volatility market } \\
\hline LCAPM & $\begin{array}{l}0.949 \\
{[0.835]}\end{array}$ & $\begin{array}{l}0.670 \\
{[0.959]}\end{array}$ & & & & & & $\begin{array}{l}0.512 \\
{[1.753]}\end{array}$ & & & \\
\hline $\mathrm{PS} 4_{i n n}$ & $\begin{array}{l}0.953 \\
{[1.609]}\end{array}$ & $\begin{array}{l}0.510 \\
{[1.314]}\end{array}$ & $\begin{array}{l}0.211 \\
{[1.445]}\end{array}$ & & $\begin{array}{l}0.411 \\
{[2.979]}\end{array}$ & & & & $\begin{array}{l}0.665 \\
{[0.172]}\end{array}$ & & \\
\hline $\mathrm{PS} 4_{t r d}$ & $\begin{array}{l}1.144 \\
{[1.916]}\end{array}$ & $\begin{array}{l}0.293 \\
{[0.670]}\end{array}$ & $\begin{array}{l}0.274 \\
{[1.872]}\end{array}$ & & $\begin{array}{l}0.399 \\
{[2.966]}\end{array}$ & & & & & $\begin{array}{l}2.382 \\
{[1.906]}\end{array}$ & \\
\hline S2 & $\begin{array}{l}2.715 \\
{[3.355]}\end{array}$ & $\begin{array}{l}-0.749 \\
{[-1.025]}\end{array}$ & & & & & & & & & $\begin{array}{l}0.232 \\
{[0.473]}\end{array}$ \\
\hline $\mathrm{FF} 5+L F$ & $\begin{array}{l}1.146 \\
{[0.756]}\end{array}$ & $\begin{array}{l}0.286 \\
{[0.280]}\end{array}$ & & $\begin{array}{l}0.314 \\
{[2.155]}\end{array}$ & $\begin{array}{l}0.437 \\
{[3.176]}\end{array}$ & $\begin{array}{l}0.266 \\
{[0.998]}\end{array}$ & $\begin{array}{l}-0.451 \\
{[-1.386]}\end{array}$ & $\begin{array}{l}-0.353 \\
{[-1.285]}\end{array}$ & & & \\
\hline $\mathrm{FF} 5+P S_{i n n}$ & $\begin{array}{l}0.731 \\
{[0.611]}\end{array}$ & $\begin{array}{l}0.708 \\
{[1.237]}\end{array}$ & & $\begin{array}{l}0.319 \\
{[2.080]}\end{array}$ & $\begin{array}{l}0.415 \\
{[2.856]}\end{array}$ & $\begin{array}{l}0.410 \\
{[1.351]}\end{array}$ & $\begin{array}{l}-0.384 \\
{[-1.085]}\end{array}$ & & $\begin{array}{l}-2.250 \\
{[-0.411]}\end{array}$ & & \\
\hline $\mathrm{FF} 5+P S_{t r d}$ & $\begin{array}{l}1.204 \\
{[1.548]}\end{array}$ & $\begin{array}{l}0.231 \\
{[0.425]}\end{array}$ & & $\begin{array}{l}0.313 \\
{[2.079]}\end{array}$ & $\begin{array}{l}0.432 \\
{[3.179]}\end{array}$ & $\begin{array}{l}0.222 \\
{[0.975]}\end{array}$ & $\begin{array}{l}-0.492 \\
{[-1.481]}\end{array}$ & & & $\begin{array}{l}2.129 \\
{[1.861]}\end{array}$ & \\
\hline $\mathrm{FF} 5+S F$ & $\begin{array}{l}1.929 \\
{[2.327]}\end{array}$ & $\begin{array}{l}-0.117 \\
{[-0.170]}\end{array}$ & & $\begin{array}{l}0.214 \\
{[1.153]}\end{array}$ & $\begin{array}{l}0.521 \\
{[2.807]}\end{array}$ & $\begin{array}{l}0.545 \\
{[1.410]}\end{array}$ & $\begin{array}{l}-0.926 \\
{[-1.812]}\end{array}$ & & & & $\begin{array}{l}0.057 \\
{[0.237]}\end{array}$ \\
\hline \multicolumn{12}{|c|}{ High-volatility market } \\
\hline LCAPM & $\begin{array}{l}1.407 \\
{[1.322]}\end{array}$ & $\begin{array}{l}-0.901 \\
{[-1.125]}\end{array}$ & & & & & & $\begin{array}{l}1.000 \\
{[2.482]}\end{array}$ & & & \\
\hline $\mathrm{PS}_{i n n}$ & $\begin{array}{l}2.002 \\
{[3.300]}\end{array}$ & $\begin{array}{l}-1.566 \\
{[-2.656]}\end{array}$ & $\begin{array}{l}-0.022 \\
{[-0.100]}\end{array}$ & & $\begin{array}{l}0.274 \\
{[1.348]}\end{array}$ & & & & $\begin{array}{l}2.121 \\
{[1.421]}\end{array}$ & & \\
\hline $\mathrm{PS}_{t r d}$ & $\begin{array}{l}2.165 \\
{[3.668]}\end{array}$ & $\begin{array}{l}-1.732 \\
{[-2.976]}\end{array}$ & $\begin{array}{l}-0.043 \\
{[-0.202]}\end{array}$ & & $\begin{array}{l}0.337 \\
{[1.660]}\end{array}$ & & & & & $\begin{array}{l}0.510 \\
{[0.365]}\end{array}$ & \\
\hline S2 & $\begin{array}{l}1.567 \\
{[1.086]}\end{array}$ & $\begin{array}{l}-1.234 \\
{[-1.111]}\end{array}$ & & & & & & & & & $\begin{array}{l}0.223 \\
{[0.798]}\end{array}$ \\
\hline $\mathrm{FF} 5+L F$ & $\begin{array}{l}1.397 \\
{[1.455]}\end{array}$ & $\begin{array}{l}-0.990 \\
{[-1.278]}\end{array}$ & & $\begin{array}{l}0.071 \\
{[0.347]}\end{array}$ & $\begin{array}{l}0.246 \\
{[1.223]}\end{array}$ & $\begin{array}{l}0.636 \\
{[1.604]}\end{array}$ & $\begin{array}{l}0.272 \\
{[0.693]}\end{array}$ & $\begin{array}{l}0.851 \\
{[2.546]}\end{array}$ & & & \\
\hline $\mathrm{FF} 5+P S_{i n n}$ & $\begin{array}{l}1.807 \\
{[2.477]}\end{array}$ & $\begin{array}{l}-1.403 \\
{[-2.129]}\end{array}$ & & $\begin{array}{l}0.073 \\
{[0.350]}\end{array}$ & $\begin{array}{l}0.249 \\
{[1.231]}\end{array}$ & $\begin{array}{l}0.548 \\
{[1.480]}\end{array}$ & $\begin{array}{l}0.208 \\
{[0.453]}\end{array}$ & & $\begin{array}{l}0.951 \\
{[0.443]}\end{array}$ & & \\
\hline $\mathrm{FF} 5+P S_{t r d}$ & $\begin{array}{l}1.624 \\
{[2.520]}\end{array}$ & $\begin{array}{l}-1.212 \\
{[-2.038]}\end{array}$ & & $\begin{array}{l}0.073 \\
{[0.353]}\end{array}$ & $\begin{array}{l}0.249 \\
{[1.215]}\end{array}$ & $\begin{array}{l}0.552 \\
{[1.542]}\end{array}$ & $\begin{array}{l}0.437 \\
{[0.940]}\end{array}$ & & & $\begin{array}{l}-0.575 \\
{[-0.383]}\end{array}$ & \\
\hline $\mathrm{FF} 5+S F$ & 1.920 & -1.602 & & 0.019 & 0.155 & 0.667 & 0.142 & & & & 0.096 \\
\hline
\end{tabular}




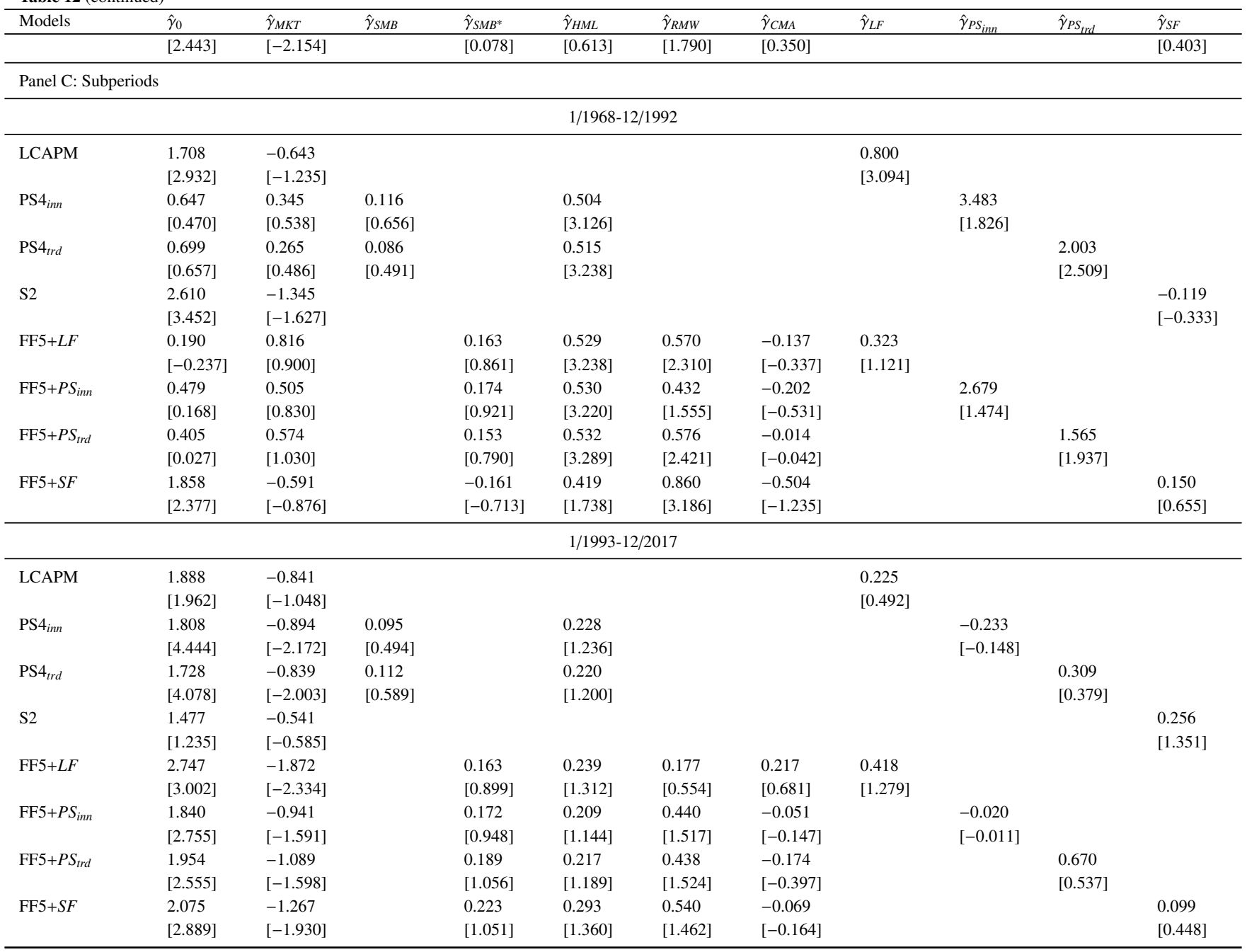

Note: This table presents the premium estimates associated with the factor loadings. In addition to the original liquidity-risk-based models, our tests also add each of the liquidity factors to the FF5. The symbol S2 stands for the Sadka (2006) two-factor model, FF5 $+P S_{t r d}$ for the FF5 extended by the PS traded liquidity factor, and similarly for others. Number in square brackets are the Kan et al.(2013) $t$-statistics $\left(t_{K R S}\right)$

\subsection{Can competing models explain the liquidity risk factor of the LCAPM $(18)$ ?}

The previous results suggest that the trading-discontinuity-based liquidity risk factor $(L F)$ and the corresponding LCAPM perform well relative to other liquidity-risk- and non-liquidity-risk-based models. This raises the natural question: Can competing models explain $L F$ ? To address this question, we regress $L F$ on each model's factors across different economic states and over two subperiods. A non-zero regression intercept implies that liquidity risk captured by $L F$ has the explanatory power beyond other factors.

Table 13, Panel A shows that all the five models fail to subsume the trading-discontinuity-based liquidity risk factor $(L F)$ of the LCAPM (18) over each of the two subperiods. After adjusting for the factors within HXZ4, for instance, the $L F$ remains significant at $0.5 \%(t=3.364)$ per month over 1968-1992 and 0.9\% $(t=6.06)$ per month over 1993-2017. By inspecting the results in Panels B and C, all the competing models considered are again not able to account for $L F$ across up and down markets 
as well as high- and low-volatility markets. Consistent with the economic intuition, the price of liquidity risk is high during market downturns. For example, after adjusting for the FF5, the $L F$ alpha is $0.9 \%(t=4.126)$ per month in the up market, whereas it is $1.8 \%(t=7.945)$ in the down market ${ }^{13}$ Overall, the evidence suggests that the liquidity risk factor of the LCAPM (18) is robust to any competing models considered. Liquidity risk captured by the liquidity risk factor $(L F)$ of the LCAPM has the unique power beyond the existing factors to describe the cross-section of average stock returns.

\section{Table 13}

Results of regressing $L F$ of the LCAPM on each other model's factors.

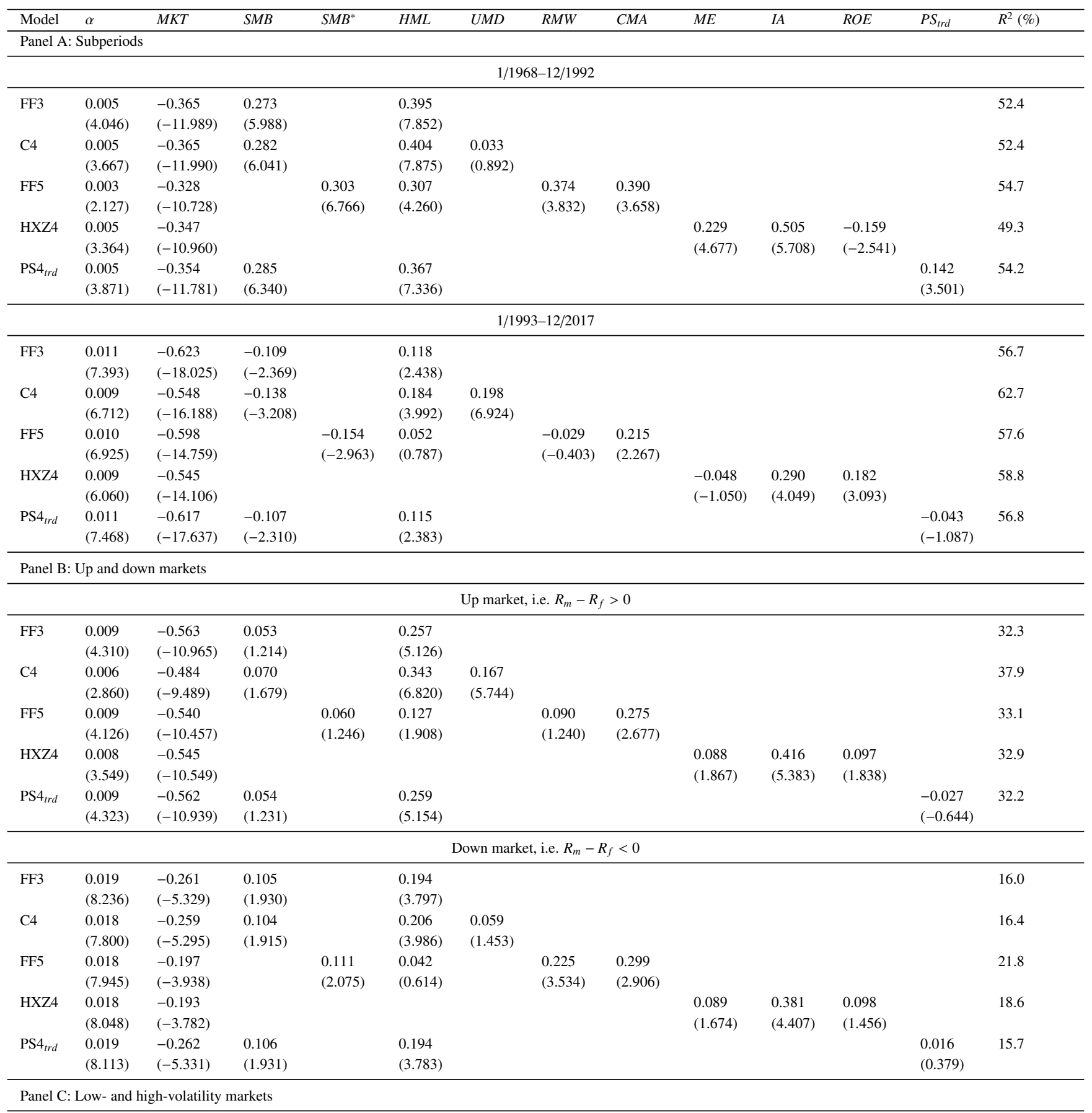

Low-volatility market

\footnotetext{
${ }^{13}$ We also regress the traded PS factor $\left(P S_{t r d}\right)$. Untabulated results show that, except for the full sample period and the high-volatility period, $P S_{t r d}$ can be captured by most of the competing models.
} 


\begin{tabular}{|c|c|c|c|c|c|c|c|c|c|c|c|c|c|}
\hline Model & $\alpha$ & $M K T$ & $S M B$ & $S M B^{*}$ & $H M L$ & $U M D$ & $R M W$ & $C M A$ & $M E$ & $I A$ & $R O E$ & $P S_{\text {trd }}$ & $R^{2}(\%)$ \\
\hline FF3 & $\begin{array}{l}0.010 \\
(7.919)\end{array}$ & $\begin{array}{l}-0.552 \\
(-13.594)\end{array}$ & $\begin{array}{l}-0.001 \\
(-0.027)\end{array}$ & & $\begin{array}{l}0.311 \\
(5.800)\end{array}$ & & & & & & & & 47.6 \\
\hline FF5 & $\begin{array}{l}0.010 \\
(7.317)\end{array}$ & $\begin{array}{l}-0.515 \\
(-12.246)\end{array}$ & & $\begin{array}{l}0.038 \\
(0.734)\end{array}$ & $\begin{array}{l}0.186 \\
(2.397)\end{array}$ & & $\begin{array}{l}0.211 \\
(2.275)\end{array}$ & $\begin{array}{l}0.327 \\
(2.885)\end{array}$ & & & & & 49.0 \\
\hline HXZ4 & $\begin{array}{l}0.011 \\
(7.658)\end{array}$ & $\begin{array}{l}-0.554 \\
(-13.444)\end{array}$ & & & & & & & $\begin{array}{l}-0.017 \\
(-0.314)\end{array}$ & $\begin{array}{l}0.440 \\
(5.390)\end{array}$ & $\begin{array}{l}-0.042 \\
(-0.607)\end{array}$ & & 47.2 \\
\hline $\mathrm{PS}_{t r d}$ & $\begin{array}{l}0.011 \\
(8.237)\end{array}$ & $\begin{array}{l}-0.566 \\
(-13.996)\end{array}$ & $\begin{array}{l}-0.020 \\
(-0.404)\end{array}$ & & $\begin{array}{l}0.311 \\
(5.866)\end{array}$ & & & & & & & $\begin{array}{l}-0.124 \\
(-2.864)\end{array}$ & 48.8 \\
\hline \multicolumn{14}{|c|}{ High-volatility market } \\
\hline FF3 & $\begin{array}{l}0.006 \\
(3.854)\end{array}$ & $\begin{array}{l}-0.471 \\
(-14.847)\end{array}$ & $\begin{array}{l}0.114 \\
(2.381)\end{array}$ & & $\begin{array}{l}0.207 \\
(4.081)\end{array}$ & & & & & & & & 49.6 \\
\hline $\mathrm{C} 4$ & $\begin{array}{l}0.005 \\
(3.301)\end{array}$ & $\begin{array}{l}-0.431 \\
(-13.780)\end{array}$ & $\begin{array}{l}0.114 \\
(2.495)\end{array}$ & & $\begin{array}{l}0.270 \\
(5.401)\end{array}$ & $\begin{array}{l}0.159 \\
(5.331)\end{array}$ & & & & & & & 53.8 \\
\hline FF5 & $\begin{array}{l}0.004 \\
(2.573)\end{array}$ & $\begin{array}{l}-0.427 \\
(-12.604)\end{array}$ & & $\begin{array}{l}0.138 \\
(2.754)\end{array}$ & $\begin{array}{l}0.044 \\
(0.669)\end{array}$ & & $\begin{array}{l}0.192 \\
(2.997)\end{array}$ & $\begin{array}{l}0.286 \\
(2.793)\end{array}$ & & & & & 51.5 \\
\hline HXZ4 & $\begin{array}{l}0.004 \\
(2.280)\end{array}$ & $\begin{array}{l}-0.432 \\
(-13.056)\end{array}$ & & & & & & & $\begin{array}{l}0.145 \\
(3.040)\end{array}$ & $\begin{array}{l}0.356 \\
(4.334)\end{array}$ & $\begin{array}{l}0.154 \\
(2.810)\end{array}$ & & 51.3 \\
\hline $\mathrm{PS}_{t r d}$ & $\begin{array}{l}0.006 \\
(3.628)\end{array}$ & $\begin{array}{l}-0.473 \\
(-14.896)\end{array}$ & $\begin{array}{l}0.109 \\
(2.280)\end{array}$ & & $\begin{array}{l}0.202 \\
(3.969)\end{array}$ & & & & & & & $\begin{array}{l}0.050 \\
(1.195)\end{array}$ & 49.6 \\
\hline
\end{tabular}

Note: Numbers in parentheses are $t$-statistics.

\section{Conclusion}

Although researchers and practitioners has long recognized the importance of liquidity risk, recent literature appears to overlook its role played in asset pricing. The neglect is largely derived from the use of the price-impact-based liquidity factor of Pástor and Stambaugh (2003) as a representative to assess the explanatory power of liquidity risk. We argue that neglecting the power of liquidity risk to explain expected stock returns may be premature because there are other liquidity risk factors proposed in the literature. Thus, this paper first evaluates three liquidity risk factors/models developed by Pástor and Stambaugh (2003), Sadka (2006), and Liu (2006). The evidence shows that the trading-discontinuity-based liquidity risk factor of Liu (2006) exhibits significant pricing power and the corresponding LCAPM (18) performs well in explaining the cross-section of expected stock returns. In contrast, the price-impact-based liquidity factors/models of Pástor and Stambaugh (2003) and Sadka (2006) lack significant pricing ability. Then, we investigate the performance of the LCAPM in comparison with the commonly used and newly developed non-liquidity-risk-based models such as the Fama-French three- and five-factor models. The results reveal that the LCAPM is also preferable to the non-liquidity models examined. Consistent with the economic intuition, liquidity risk captured by the LCAPM reflects changes in the business cycle. We further demonstrate the irreplaceability of liquidity risk by showing that the information captured by the trading-discontinuity-based liquidity risk factor cannot be subsumed by all other factors/models, indicating that the power of liquidity risk goes beyond the existing factors/models to explain asset returns. Our evidence indicates that the unimportance of liquidity risk the recent studies reveal is an overgeneralization from the use of only one of the liquidity factors in the model performance evaluation. Overall, the results presented in this paper verify the importance of liquidity risk in asset pricing, identify the LCAPM as an adequate model, and underscore the practical relevance 
of liquidity risk for corporate investment appraisal, portfolio construction, performance evaluation, and financial economics research such as tests of market efficiency. 


\section{Reference}

[1] Acharya, V. V., Pedersen, L. H., 2005. Asset pricing with liquidity risk. J. Financ. Econ. 77 (2), 375-410.

[2] Ahmed, S., Bu, Z., Tsvetanov, D., 2019. Best of the Best: a comparison of factor models. J. Financ. Quant. Anal. 54 (4), $1713-1758$.

[3] Amihud, Y., 2002. Illiquidity and stock returns: cross-section and time-series effects. J. Financial Mark. 5 (1), 31-56.

[4] Amihud, Y., Mendelson, H., 1986. Asset pricing and the bid-ask spread. J. Financ. Econ. 17 (2), 223-249.

[5] Barillas, F., Kan, R., Robotti, C., Shanken, J., 2019. Model comparison with Sharpe ratios. J. Financ. Quant. Anal. doi:10.1017/S0022109019000589.

[6] Barillas, F., Shanken, J., 2017. Which alpha? Rev. Financ. Stud. 30 (4), 1316-1338.

[7] Barillas, F., Shanken, J., 2018. Comparing asset pricing models. J. Finance 73 (2), 715-754.

[8] Bekaert, G., Harvey, C.R., Lundblad C., 2007. Liquidity and expected returns: Lessons from emerging markets. Rev. Financ. Stud. 20 (6), 1783-1831.

[9] Ben-Rephael, A., Kadan, O., Wohl, A., 2015. The diminishing liquidity premium. J. Financ. Quant. Anal. 50, $197-229$.

[10] Brennan, M. J., Chordia, T., Subrahmanyam, A., 1998. Alternative factor specifications, security characteristics, and the cross-section of expected stock returns. J. Financ. Econ. 49 (3), 345-373.

[11] Brennan, M.J., Subrahmanyam, A., 1996. Market microstructure and asset pricing: On the compensation for illiquidity in stock returns. J. Financ. Econ. 41, 441-464.

[12] Brunnermeier, M. K., Pedersen., L. H., 2009. Market liquidity and funding liquidity. Rev. Financ. Stud. 22 (6), $2201-2238$.

[13] Butler, A. W., Grullon, G., Weston, J. P., 2005. Stock market liquidity and the cost of issuing equity. J. Financ. Quant. Anal. 40 (2), $331-348$.

[14] Carhart, M.M., 1997. On persistence in mutual fund performance. J. Finance 52 (1), 57-82.

[15] Corwin, S.A., Schultz, P., 2012. A simple way to estimate bid-ask spreads from daily high and low prices. J. Finance 67 (2), $719-760$.

[16] Datar, V. T., Naik, N. Y., Radcliffe, R., 1998. Liquidity and asset returns: An alternative test. J. Financial Mark. 1 (2), $203-219$.

[17] Dong, X., Feng, S., Sadka, R., 2019. Liquidity risk and mutual fund performance. Manage Sci. 65 (3), 1020-1041.

[18] Fall, M., Louhichi, W., Viviani, J.L., 2019. Empirical tests on the asset pricing model with liquidity risk: An unobserved components approach. Econ. Modell. 80, 75-86.

[19] Fama, E.F., French, K.R., 1993. Common risk factors in the returns on stocks and bonds. J. Financ. Econ. 33, 3-56. 
[20] Fama, E.F., French, K.R., 2015. A five-factor asset pricing model. J. Financ. Econ. 116 (1), 1-22.

[21] Fama, E.F., French, K.R., 2016. Dissecting anomalies with a five-factor model. Rev. Financ. Stud. 29 (1), 69-103.

[22] Fama, E.F., French, K.R., 2018. Choosing factors. J. Financ. Econ. 128 (2), 234-252.

[23] Feng, G., Giglio, S., Xiu, D., 2020. Taming the factor zoo: A test of new factors. J. Finance, 2020, 75 (3), $1327-1370$.

[24] Garleanu, N., Pedersen, L. H., 2013. Dynamic trading with predictable returns and transaction costs. J. Finance 68 (6), $2309-2340$.

[25] Gospodinov, N., Kan, R., Robotti, C., 2013. Chi-squared tests for evaluation and comparison of asset pricing models. J. Econom. 173 (1), 108-125.

[26] Hameed, A., Kang, W., Viswanathan, S., 2010. Stock market declines and liquidity. J. Finance 65 (1), 257-293.

[27] Hasbrouck, J., 2009. Trading costs and returns for U.S. equities: Estimating effective costs from daily data. J. Finance 64 (3), $1445-1477$.

[28] Hou, K., Mo, Hai., Xue, C., Zhang, L., 2019. Which factors? Rev. Financ. 23, 1-35.

[29] Hou, K., Xue, C., Zhang, L., 2015. Digesting anomalies: an investment approach. Rev. Financ. Stud. 28 (3), 650-705.

[30] Hou, K., Xue, C., Zhang, L., 2017. A comparison of new factor models. Working paper, No. 2015-03-05, Fisher College of Business, U.S.A.

[31] Jagannathan, R., Wang, Y., 2007. Lazy investors, discretionary consumption, and the cross-section of stock returns. J. Finance 62 (4), $1623-1661$.

[32] Jagannathan, R., Wang, Z., 1998. An asymptotic theory for estimating beta-pricing models using cross-sectional regression. J. Finance. $53(4), 1285-1309$.

[33] Kamara, A., Lou, X., Sadka, R., 2008. The divergence of liquidity commonality in the cross-section of stocks. J. Financ. Econ. 89 (3), 444-466.

[34] Kan, R., Robotti, C., Shanken, J., 2013. Pricing model performance and the two-pass cross-sectional regression methodology. J. Finance 68 (6), 2617-2649.

[35] Lee, K. H., 2011. The world price of liquidity risk. J. Financ. Econ. 99 (1), 136-161.

[36] Lewellen, J., Nagel, S., Shanken, J., 2010. A skeptical appraisal of asset pricing tests. J. Financ. Econ. 96 (2), $175-194$.

[37] Li, H., Novy-Marx, R., Velikov, M., 2019. Liquidity risk and asset pricing. Crit. Finance Rev. 8 (1-2), 223-255.

[38] Lipson, M. L., Mortal, S., 2009. Liquidity and capital structure. J. Financial Mark. 12 (4), 611-644.

[39] Liu, W., 2006. A liquidity-augmented capital asset pricing model. J. Financ. Econ. 82 (3), 631-671. 
[40] Lou, X., Sadka, R., 2011. Liquidity level or liquidity risk? evidence from the financial crisis. Financial Anal. J. 67 (3), 51-62.

[41] Maio, P., Santa-Clara, P., 2012. Multifactor models and their consistency with the ICAPM. J. Financ. Econ. 106 (3), $586-613$.

[42] Momani, M.Q.M., 2018. Revisiting Pastor-Stambaugh liquidity factor. Econ. lett. 163, 190-192.

[43] Næs, R., Skjeltorp, J. A., Ødegaard B. A., 2011. Stock market liquidity and the business cycle. J. Finance 66 (1), $139-176$.

[44] Pástor, L., Stambaugh, R.F., 2003. Liquidity risk and expected stock returns. J. Polit. Econ. 111 (3), 642-685.

[45] Petkova, R., 2006. Do the Fama-French factors proxy for innovations in predictive variables? J. Finance 61 (2), $581-612$.

[46] Sadka, R., 2006. Momentum and post-earnings-announcement drift anomalies: The role of liquidity risk. J. Financ. Econ. 80 (2), 309 349.

[47] Sha, Y., Gao, R., 2019. Which is the best: a comparison of asset pricing factor models in Chinese mutual fund industry. Econ. Modell. $83,8-16$.

[48] Shanken, J., 1992. On the estimation of beta-pricing models. Rev. Financ. Stud. 5(1), 1-33.

[49] Shanken, J., Zhou, G., 2007. Estimating and testing beta pricing models: Alternative methods and their performance in simulations. J. Financ. Econ. 84 (1), 40-86.

[50] Wolak, F.A., 1987. An exact test for multiple inequality and equality constraints in the linear regression model. J. Am. Stat. Assoc. 82 (399), 782-793.

[51] Wolak, F.A., 1989. Testing inequality constraints in linear econometric models. J. Econom. 41 (2), 205-235. 